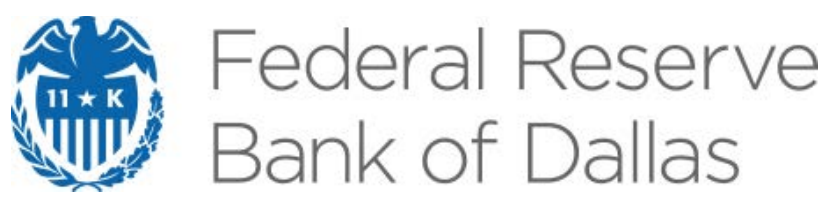

\title{
Demographics and the Evolution of Global Imbalances
}

Michael Sposi

\section{Globalization Institute Working Paper 332}

Research Department

https://doi.org/10.24149/gwp332r1

Working papers from the Federal Reserve Bank of Dallas are preliminary drafts circulated for professional comment. The views in this paper are those of the authors and do not necessarily reflect the views of the Federal Reserve Bank of Dallas or the Federal Reserve System. Any errors or omissions are the responsibility of the authors. 


\title{
Demographics and the Evolution of Global Imbalances*
}

\author{
Michael Sposi ${ }^{\dagger}$
}

December 2017

Revised: April 15, 2019

\begin{abstract}
The age distribution evolves asymmetrically across countries, influencing relative saving rates and labor supply. Emerging economies experienced faster increases in working age shares than advanced economies did. Using a dynamic, multicountry model I quantify the effect of demographic changes on trade imbalances across 28 countries since 1970. Counterfactually holding demographics constant reduces net exports in emerging economies and boosts them in advanced economies. On average, a one percentage point increase in a country's working age share, relative to the world, increases its ratio of net exports to GDP by one-third of a percentage point. These findings alleviate the allocation puzzle.
\end{abstract}

Keywords: Demographics, Trade imbalances, Dynamics, Labor supply

JEL Codes: F11, F21, J11

\footnotetext{
* I am grateful to George Alessandria, Mario Crucini, Mick Devereux, Jonathan Eaton, Andy Glover, Karen Lewis, Kanda Naknoi, Kim Ruhl, Jake Short, Joe Steinberg, Mark Wynne, and Kei-Mu Yi for helpful comments. This paper also benefited from audiences at the Bank of Canada, Dallas Fed, Penn State, University of Toronto, and UConn as well as conference participants at Midwest Macroeconomics Meetings and System Committee for International Economic Analysis. Kelvin Virdi provided excellent research assistance. The views in the paper are those of the author and do not necessarily reflect the views of the Federal Reserve Bank of Dallas or the Federal Reserve System.

${ }^{\dagger}$ Michael Sposi, Southern Methodist University and Federal Reserve Bank of Dallas. SMU - 3300 Dyer Street, Dallas, TX 75275. Phone: 214-768-2806; Email: msposi@smu.edu.
} 


\section{Introduction}

Recently, trade imbalances have taken center stage in many high-level policy debates. Absent business cycle fluctuations, these imbalances demonstrate highly persistent and low frequency trends. For instance, the United States has run an annual trade deficit for about four decades, and China a surplus for over two decades. In 2017, the median absolute value of net exports to GDP was about 7 percent (across 159 countries in the World Bank's World Development Indicators). Imbalances can arise for a multitude of reasons such as asymmetric trade costs due to various policies, frictions on cross-border financial transactions, distortions on saving decisions, and because of natural forces such as demographic-induced differences in saving behavior. Existing research has yet to systematically disentangle the effects of such forces across many countries in a general equilibrium setting.

In recent history, countries have undergone persistent and low frequency changes in their age distributions, defined as the young share (age 14 and below), the working age share (age 15-64), and the retired share (age 65 and above). These moments influence a country's propensity to save, to supply labor and produce, and thus exert pressure on the balance sheets of large pensions, on returns to capital, and ultimately on trade imbalances.

Figure 1 shows the observed and projected working age shares for 28 countries from 1970-2060. In general, emerging economies have experienced faster increases in their working age shares compared to advanced economies, and some are projected to experience future increases. Aside from South Korea, China experienced the fastest increase from 1970-2014 among all countries, and is also projected to experience the fastest decline from 2015-2060. Many advanced economies including the United States, on the other hand, have experienced relatively flat, and often decreasing, working age shares with declines projected to continue.

This paper incorporates these demographic forces into a dynamic, multicountry, general equilibrium model to study the consequences for trade imbalances across 28 countries since 1970. The model features bilateral trade between all countries, endogenous trade imbalances through trade in one-period bonds, physical capital accumulation, and endogenous labor supply. To my knowledge, this is the first model to combine all of these features in a multicountry environment and compute exact transitional dynamics.

Aggregate saving is determined by a combination of forces, including demographics which directly influence a country's propensity to save. Saving itself is equal to the sum of net exports and domestic investment, so the model is built to structurally disentangle the two.

The pattern of bilateral trade flows, which has immediate implications for the trade 
Figure 1: Working age share

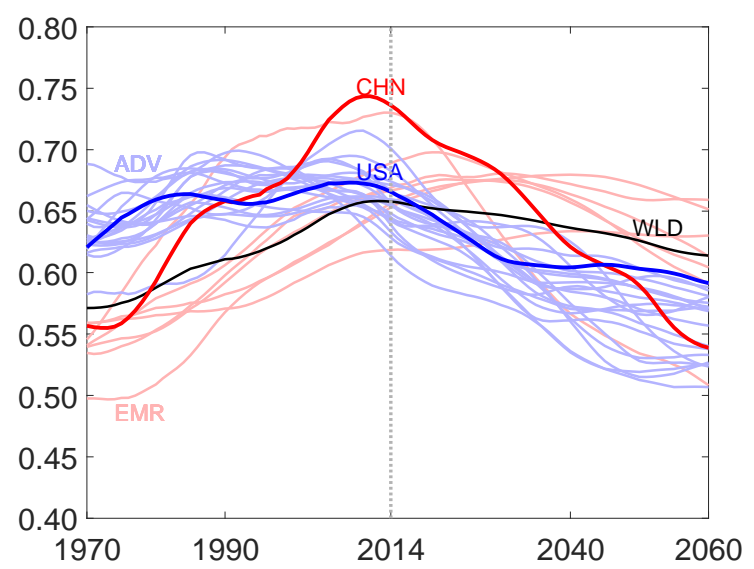

Notes: Emerging economies (EMR) in red include Brazil, China, India, Indonesia, South Korea, Mexico, Turkey, and the rest-of-world aggregate. Advanced economies (ADV) in blue include the remaining 20 countries. The working age share for the world (WLD) in black is constructed as the population-weighted average across all 28 countries.

balance, are driven primarily by asymmetric productivity growth and changes in trade costs. At the same time, a country's trade balance is equal to the difference between its saving and investment. Thus, forces that influence investment have implications for the trade balance. Differential productivity growth along with distortions to capital markets are key determinants of returns to investment. International borrowing and lending in one-period bonds induces cross-border capital flows in search of high returns to investment.

The model also features endogenous labor supply that is affected by both demographics and distortions. Changes in labor supply influence returns to investment through their effect on the capital-labor ratio, and also affect a country's productive capacity and therefore its ability to fund its liabilities using domestic resources.

I find that cross-country differences in changes in the age distribution help systematically explain both the direction and magnitude of trade imbalances. The main counterfactual freezes every country's age distribution at their 1970 levels and computes the resulting equilibrium dynamics. On average, a one percentage point increase in a country's working age share, relative to that of the world, implies a one-third percentage point increase in its net exports to GDP. Moreover, the observed demographics contributed positively to net exports in emerging economies with quickly rising working age shares, and contributed negatively to net exports in advanced economies with slowly rising, or even decreasing, working age shares. The systematic relationship between economic growth and changes in the age distri- 
bution provides a channel in which resources flow from fast-growing emerging economies to slower-growing advanced economies, helping alleviate the allocation puzzle. In the counterfactual, the elasticity of the ratio of net exports to GDP with respect to contemporaneous TFP growth is $-19.4 \%$, compared to $7.5 \%$ in the data.

To draw a specific contrast, China's observed working age share increased at double the rate (from 0.56 to 0.73 ) of the entire world's (from 0.57 to 0.66). In particular, from 1990-2014 China experienced a demographic window - a period in which the support ratio is favorable for saving - and capitalized through high national saving rates, boosting net exports 11 In the main counterfactual with the age distribution frozen at 1970 levels in every country, China runs a large trade deficit, rather than a surplus. Conversely, since 1970 the United States' working age share increased at half the rate of the entire world's (from 0.62 to 0.66 ). In the same counterfactual, U.S. net exports are elevated by about one-third of a percent of GDP per year, relative to the data. Not only is the U.S. trade deficit lower on average, but the long-run widening of the deficit is also attenuated. From 1970 to 2014, observed U.S. net exports decline by 3.4 percentage points (from 0.2 to -3.2 percent of GDP), while in the counterfactual they decline by 2.4 percentage points (from -0.3 to -2.7 percent).

Asymmetric population growth across countries is also a relevant demographic characteristic in its own right. Similar to the neoclassical growth model in a closed economy, when population growth is relatively high, households have a greater propensity to save to ensure that consumption is smoothed out over time on a per-capita basis. However, in an open economy saving can be achieved through net exports, particularly when domestic investment opportunities are limited. In the open economy population size affects the terms of trade, a channel that is absent in models that ignore gross bilateral trade flows. A fast growing population lowers the real exchange rate, as foreign import penetration accounts for a declining share of gross absorption. In turn, the real interest rate declines inducing capital to flow out in search of higher rates of return, i.e., increasing net exports.

Section 2 builds the foundation for the demand-side of the model starting from a representative household. In this setting there is no explicit notion of heterogeneity in age either within or across countries. Instead, information about the age distribution is embedded in two types of preference shocks: (i) saving shocks (changes in the marginal utility of intertemporal consumption) and (ii) labor shocks (changes in the marginal utility of leisure). Section 2.1 provides microfoundations connecting the preference shocks with changes in the age dis-

\footnotetext{
${ }^{1} \mathrm{~A}$ demographic window is defined by the United Nations as a period of time when "the fraction of the population under age 15 falls below 30 percent and the fraction of the population 65 years and older is still below 15 percent."
} 
tribution arising from an overlapping-generations framework. In Section 2.2 the preference shocks are juxtaposed alongside distortions to net-foreign income and distortions to labor income, so that the product of each preference shock and the corresponding distortion can be measured as a wedge in an Euler equation, given data on some prices and quantities.

The microfoundations guide an empirical decomposition of these wedges into a demographic component (preference shocks) and a non-demographic component (distortions). The decomposition projects the calibrated wedges onto observed moments of the age distribution across countries and over time, and the preference shocks are recovered as the component that covaries with these moments. Since the wedges fully account for each country's saving behavior, the distortionary component captures non-demographic aspects explored by the literature, including financial market distortions and labor market distortions. The decomposition serves as a disciplining device to study counterfactuals in which alterations to the age distribution are manifested in alterations to the preference shocks.

Section 3 embeds the representative household into a general equilibrium environment, and imposes structure on the supply side to discipline how prices respond to counterfactual demographic transition paths. In particular, the supply side features competitive firms, international trade, borrowing and lending between countries, and physical capital accumulation. Differential paths of productivity growth combined with changing bilateral trade costs shape the pattern of international trade flows, yielding direct implications for trade imbalances. In addition, differential rates of productivity growth and distortions to investment each affect return differentials across countries and, hence, current account dynamics.

In Section 4 the general equilibrium model is calibrated to exactly match annual transitions in 27 countries and a rest-of-world aggregate from 1970-2060. Targets include various quantities (public plus private consumption, investment, and bilateral trade flows), and various prices (of consumption goods, investment goods, tradable goods, and labor). Data from 1970-2014 are observed, while data from 2015-2060 are based on long-term projections. Incorporating projections provides external discipline to households' expectations during the period of interest: 1970-2014. It also significantly reduces the impact that terminal conditions impose on saving behavior during that period. I employ a wedge-accounting procedure that assigns parameter values to rationalize both the observed and projected data as a solution to a perfect-foresight equilibrium.

Section 5 analyzes outcomes arising from counterfactual paths for age distributions by constructing counterfactual paths for preference shocks. Each type of preference shock provides a distinct channel through which demographics affect trade imbalances. First, a higher 
working age share implies a higher saving shock, i.e., a greater demand for future consumption relative to current consumption. This directly implies that there will be higher contemporaneous demand for saving and higher net exports.

Second, a higher working age share implies a lower labor shock (lower marginal utility of leisure), which in turn induces two indirect and opposing effects. On the one hand, a lower labor shock implies higher labor supply and productive capacity. As a result, a country will borrow less to fund its liabilities and will have contemporaneously higher demand for saving and net exports. On the other hand, higher labor supply stemming from the lower labor shock raises the marginal product of capital. As international financial resources chase labor, this triggers an inflow of borrowing and reduces net exports. As a result, the quantitative effects of demographics arise primarily through the direct saving channel.

I also measure how much various forces have contributed to the allocation puzzle. I find that changes in bilateral trade costs and in labor market distortions do not individually help reconcile the allocation puzzle. Changes in saving distortions account for the most, followed by changes in the age distribution, and then changes in investment distortions.

\section{$1.1 \quad$ Related literature}

The three closest papers on demographics and imbalances are Backus, Cooley, and Henriksen (2014), Ferrero (2010) and Krueger and Ludwig (2007). My paper differs along several margins. The first is in how households are modeled. Backus, Cooley, and Henriksen (2014) and Krueger and Ludwig (2007) both study demographics in an open economy with overlapping generations. While such a framework is natural in this context, it limits the analysis to 4 countries in the former and to 3 countries in the latter. My paper abstracts from overlapping generations and instead uses a representative household whose preferences change over time based on changes in the age distribution. This enables me to avoid value functions, which are far too intractable in a general equilibrium environment with a large number of countries. Ferrero (2010) incorporates demographics into a two-country model with two types of agents: workers and retirees. Workers transition into retirement with a time-varying probability and retirees exit the model with a time-varying probability, making the problem mimic that of a representative household with a time-varying discount factor, similar to Blanchard (1985) and Yaari (1965). This apporach provides a natural bridge linking the rich demographic structure of an OLG framework to a representative household environment that I employ.

Second, each of these papers considers net aggregate trade at the country level, so gross bilateral trade is absent. That is, in these papers trade imbalances arise purely because of 
intertemporal saving decisions, and have little to due with international trade, per se. In this sense, the trade imbalance is treated purely as the difference between saving and investment, rather than the difference between exports and imports.

A separate, albeit related, literature demonstrates the importance of incorporating gross bilateral trade in the context of studying trade imbalances. For instance, Obstfeld and Rogoff (2001) postulate that trade costs have the potential to help reconcile six different puzzles in international macroeconomics, some of which directly concern external imbalances. Eaton, Kortum, and Neiman (2016) use a multi-country trade model with capital accumulation and unbalanced trade and find that trade costs do indeed quantitatively account for a few of those puzzles, including two directly related to international capital flows.

Using a multicountry model, Reyes-Heroles (2016) argues that the increased ratio of global trade to global GDP accounts for the rise in the ratio of global imbalances to global GDP. In his paper, declining trade costs over time generate larger gross trade volumes, thereby amplifying the net trade positions as a share of GDP. While his analysis does not focus on explaining heterogeneity in country-level imbalances, his finding illustrates the importance of incorporating bilateral trade into models of trade imbalances since financial imbalances are ultimately offset by trade imbalances. Thus, trade costs affect the real rate of return on borrowing and lending. However, his paper does not include investment, so the trade imbalance is not influenced by investment-driven capital flows.

Alessandria and Choi (2019) combine bilateral trade and investment in capital to study the U.S. trade imbalance using a two-country model. They document that the ratio of U.S. net exports to GDP increased in absolute value because trade increased as a share of GDP, while the ratio of net exports to trade has been relatively stationary. They argue that U.S. import costs declined faster than U.S. export costs, and that this asymmetry helps explain both the magnitude and the direction of the U.S. trade imbalance.

I incorporate bilateral trade between many countries as in Reyes-Heroles (2016) and investment as in Alessandria and Choi (2019) to study the joint evolution of trade imbalances across the world. Relative to Eaton, Kortum, and Neiman (2016) I incorporate demographics and study the allocation puzzle, a puzzle not considered in Obstfeld and Rogoff (2001).

Another closely related paper is Steinberg (2019). Using a two-country, multisector model he argues that most of the rise in the U.S. trade deficit is due to increased foreign demand for saving (global saving glut), rather than a decline in domestic saving (domestic saving drought) ${ }^{2}$ My paper abstracts from the disaggregate sectoral linkages, and instead

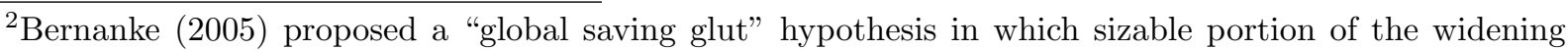


incorporates many countries over a much longer time period. This broader scope provides more variation to empirically identify a link between changes in the age distribution and the magnitude of trade imbalances. Specifically, I find a systematic relationship between demographic-induced changes in preference shocks and a country's level of economic development, thereby identifying a source for the global saving glut, while simultaneously addressing the allocation puzzle.

The allocation puzzle begins with a clear theoretical prediction: Slow-growing countries should run trade surpluses and fast-growing countries, trade deficits ${ }^{3}$ However, a great deal of empirical evidence stands in contrast to this prediction (see Gourinchas and Jeanne, 2013, Prasad, Rajan, and Subramanian, 2007). In my sample of 28 countries from 1970-2014, the elasticity of the ratio of net exports to GDP with respect to contemporaneous TFP growth is $7.5 \%$. Not only is this elasticity small, it is positive, confirming the allocation puzzle.

Gourinchas and Jeanne (2013) argue that the allocation puzzle is one about saving and not investment, and in particular, public saving. Specifically, they compute saving wedges in a similar manner as in my paper and show that these wedges are highly correlated with economic growth rates across countries. My analysis makes progress by reducing the burden of the overall saving wedge by extracting a predictable demographic component that systematically accounts for puzzling aspects of external imbalances. By counterfactually freezing every country's age distribution at 1970 levels, the elasticity of the ratio of net exports to GDP with respect to contemporaneous TFP growth becomes $-19.4 \%$. That is, the economic prediction called into question by the allocation puzzle is indeed present but largely masked by demographic forces. In addition, my analysis builds on Gourinchas and Jeanne $(2013)$ by studying the transitional dynamics in a general equilibrium setting, whereas they consider steady state changes in a partial equilibrium setting.

Alfaro, Kalemli-Ozcan, and Volosovych (2008) separate cross-border capital flows into private flows and government flows and find that government saving is indeed the culprit for the allocation puzzle. I abstract from explicitly distinguishing between private and public saving by appealing to Ricardian equivalence. Still, my findings help rationalize the pattern of public saving. That is, in many countries unfunded pension and medical liabilities are substantial components of government budgets, and both the assets and liabilities of these pensions are greatly influenced by demographics. Börsch-Supan, Ludwig, and Winter (2006) reinforce this point by demonstrating the importance of demographic driven pension reform U.S. external imbalance was driven by increased demand for saving by non-U.S. residents.

${ }^{3}$ The allocation puzzle is often discussed in terms of the current account. All of the facts and findings that I describe in this context using the trade balance are also true using the current account balance. 
as a determinant of global imbalances.

While demographics help account for the allocation puzzle, the remaining distortionary component of the saving wedge is still quantitatively important. Thus, my paper does not rule out explanations proposed in the literature that point to certain distortions.

Aguiar and Amador (2011) put forward a theoretical justification that highly indebted developing countries have little incentive to invest due to the risk of being expropriated by their government. As a result, saving shows up in net exports; This is an example of an investment distortion in my model. Buera and Shin (2017) argue that financial frictions restrict the extent that investment can respond to fast GDP growth, implying that a fast growing country will tend to run a current account surplus in the short run; This is an example of a saving distortion in my model. Ohanian, Restrepo-Echavarria, and Wright (2018) point to labor market frictions. They argue that after World War II labor wedges in Latin America impeded equilibrium supply of labor, thereby reducing the marginal product of capital and repelling foreign investment; This is an example of a labor distortion in my model.

Each of these studies shed light on idiosyncratic episodes of abnormally high growth, but none systematically consider a large number of countries over a long time period. I abstract from the microfoundations underpinning these distortions and instead measure the distortions as residuals for accounting purposes in order to isolate the role of demographics.

My paper also speaks to the large and growing body of work on China, which has become the poster child for the allocation puzzle due to its rapid growth and large trade surplus. The literature has found evidence that both demographics and market distortions have been at work. Wei and Zhang (2011) argue that male-biased gender ratios encourage men to save by purchasing real estate to attract scarce female partners. Yang, Zhang, and Zhou (2012) argue that successive cohorts of young Chinese workers face increasingly flat lifecycle earnings profiles, thereby reducing household borrowing in the face of higher future aggregate productivity. İmorohoğlu and Zhao (2018a) argue that, due to China's one-child policy, the elderly rely more on personal savings to replace lacking family support during retirement. Imorohoğlu and Zhao (2018b) argue that financial constraints faced by firms are equally important as the one-child policy in accounting for the rise in China's saving rate. In Song, Storesletten, and Zilibotti (2011), financial market imperfections imply that private firms in China finance the adaptation of technology through internal savings. My findings do not rule out any of these theories but, instead, offer a systematic assessment of the role of demographic-induced saving behavior across many countries over a long time period. 
Methodologically, my paper relates to a recent strand of literature incorporating dynamics into multicountry trade models (Alvarez, 2017; Caliendo, Dvorkin, and Parro, 2015; Eaton, Kortum, Neiman, and Romalis, 2016; Ravikumar, Santacreu, and Sposi, 2018; Reyes-Heroles, 2016; Sposi, 2012; Zylkin, 2016). I extend the algorithm developed in Ravikumar, Santacreu, and Sposi (2018) to incorporate endogenous labor supply and compute exact transitional dynamics using excess demand iteration. More generally, the methods contribute to dynamic models of trade with large state spaces. For instance, Alessandria, Choi, and Ruhl (2018) solve the exact transition paths for two countries, with three state variables in each country: capital, net-foreign assets, and the stock of firms. My model has two state variables - capital and net-foreign assets - with 28 countries.

Calibration of the model builds on the wedge accounting procedure used in Eaton, Kor-

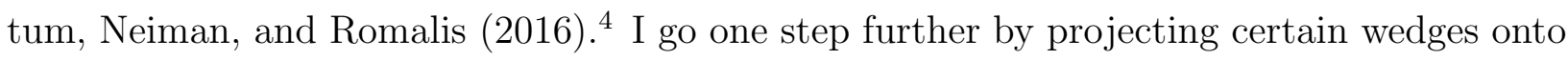
the observed age distribution to empirically isolate the effects of demographic forces.

\section{Life-cycle forces in a representative household}

This section motivates and measures how life-cycle forces can be captured by a representative household that faces preference shocks. Specifically, the preference shocks affect the intertemporal discount factor as well as the marginal utility of leisure. I first provide microfoundations for such preference shocks arising from a parsimonious economy that consists of overlapping generations (OLG) and an exogenously varying age distribution. Second, I embed the representative household into a more general environment where the preference shocks are juxtaposed alongside distortions to the net return on saving and distortions to labor income. Finally, I interact the first-order conditions with national accounts and demographics data to estimate the preference shocks and distortion processes.

\subsection{Microfounding aggregate preference shocks}

Imagine data being generated by a small open economy with OLG, where every successive cohort has identical preferences and only the age distribution changes over time. The economist observes aggregate outcomes and the age distribution, and interprets these data through the lens of a representative household model. The representative household experiences preference shocks over time. This example shows how the economist can map changes

\footnotetext{
${ }^{4}$ Wedge accounting has its roots in business cycle accounting (see Chari, Kehoe, and McGrattan, 2007).
} 
in demographics into preference shocks so that the representative household's decisions yield the same aggregate outcomes as the OLG economy.

OLG economy Agents live for two periods. At time $t$ a cohort arrives with $N_{t}^{w}$ working age agents that coexist with $N_{t}^{r}$ retirees. At time $t+1$ the working age agents from the previous period become retirees, and retirees from the previous period disappear. Working age agents choose how much labor to supply, how much to consume, and how much to save in one-period international bonds. Retirees consume their assets and do not work.

Productivity is constant over time and is such that one unit of labor generates one unit of output. I normalize the wage to 1 in every period, implying that the price of consumption is also 1 . The world interest rate on bonds, $q$, is given. Agents born at time $t$ solve

$$
\begin{aligned}
\max _{c_{t}^{w}, c_{t+1}^{r}, \ell_{t}^{w}} \ln \left(c_{t}^{w}\right)+\beta \ln \left(c_{t+1}^{r}\right)+\frac{\left(1-\ell_{t}^{w}\right)^{1-1 / \phi}}{1-1 / \phi} \\
\text { s.t. } c_{t}^{w}+\frac{c_{t}^{r}}{1+q}=\ell_{t}^{w}
\end{aligned}
$$

The solution for every cohort is characterized (implicitly) by

$$
\ell^{w}=1-\left(\frac{\ell^{w}}{1+\beta}\right)^{\phi}, \quad c^{w}=\left(1-\ell^{w}\right)^{1 / \phi}, \quad c^{r}=\beta(1+q) c^{w} .
$$

While each cohort's decision is constant over time, aggregate consumption, $C_{t}=N_{t}^{w} c_{t}^{w}+$ $N_{t}^{r} c_{t}^{r}$, and aggregate labor supply, $L_{t}=N_{t}^{w} \ell_{t}^{w}$, vary over time with demographics.

Let $s_{t}=\frac{N_{t}^{w}}{N_{t}}$ denote the working age share in the population at time $t$. Then, aggregate consumption per capita growth and the employment-population ratio, respectively, are

$$
\begin{aligned}
\frac{C_{t+1} / N_{t+1}}{C_{t} / N_{t}} & =\left(\frac{1+\left(\frac{1-\beta(1+q)}{\beta(1+q)}\right) s_{t+1}}{\beta(1+q)+(1-\beta(1+q)) s_{t}}\right) \beta(1+q), \\
\frac{L_{t}}{N_{t}} & =1-\left(\left(1-s_{t}\right)+\frac{s_{t}}{\left(\beta(1+q)+(1-\beta(1+q)) s_{t}\right)^{\phi}}\right)\left(\frac{C_{t}}{N_{t}}\right)^{\phi} .
\end{aligned}
$$

Respresentative household economy An infinitely-lived household is initially endowed with a net-foreign asset (NFA) position, $\mathcal{A}_{i 1}$. Net purchases of international bonds add to (or subtract from) the existing NFA position. In each period population is given exogenously by $N_{i t}$. The household does not explicitly experience heterogeneity in the population 
with respect to age. Instead, changes in demographics are manifested in certain "preference shocks" described below. The household values a discounted stream of population-weighted utility, where utility in each period is defined over per-capita consumption and labor supply. Each period the household earns labor income and net foreign income on bonds.

As in the OLG economy, productivity and the wage rate are both normalized to 1 in every period, so the price of consumption is also 1 . The world interest rate on bonds, $q$, is given. The representative household experiences shocks to the marginal utility of intertemporal consumption, $\psi_{t}$, and to the marginal utility of leisure, $\zeta_{t}$, and solves the following problem:

$$
\begin{aligned}
\max _{C_{t}, A_{t+1}, L_{t}} & \sum_{t=1}^{\infty} \beta \psi_{t} N_{t}\left(\ln \left(\frac{C_{t}}{N_{t}}\right)+\zeta_{t} \frac{\left(1-\frac{L_{t}}{N_{t}}\right)^{1-1 / \phi}}{1-1 / \phi}\right) \\
\text { s.t. } & C_{t}+\mathcal{A}_{t+1}=L_{t}+(1+q) \mathcal{A}_{t}
\end{aligned}
$$

The solution to the representative household's problem is

$$
\begin{aligned}
\frac{C_{t+1} / N_{t+1}}{C_{t} / N_{t}} & =\left(\frac{\psi_{t+1}}{\psi_{t}}\right) \beta(1+q), \\
\frac{L_{t}}{N_{t}} & =1-\left(\zeta_{t}\right)^{\phi}\left(\frac{C_{t}}{N_{t}}\right)^{\phi} .
\end{aligned}
$$

Combining equations (1) and (3) shows that changes in the saving shock are driven by changes in working age share. Similarly, combining equations (2) and (4) shows that changes in the labor shock are also driven by changes in the working age share. The micro-founded expressions for the preference shocks are

$$
\begin{aligned}
\frac{\psi_{t+1}}{\psi_{t}} & =\left(\frac{1+\left(\frac{1-\beta(1+q)}{\beta(1+q)}\right) s_{t+1}}{\beta(1+q)+(1-\beta(1+q)) s_{t}}\right), \\
\left(\zeta_{t}\right)^{\phi} & =\left(\left(1-s_{t}\right)+\frac{s_{t}}{\left(\beta(1+q)+(1-\beta(1+q)) s_{t}\right)^{\phi}}\right) .
\end{aligned}
$$

\subsection{Bringing the representative household to the data}

Consider $i=1, \ldots, I$ countries, each populated by a representative household. The problem faced by each household is practically identical to that described in section 2.1, with some 
modifications. First, I allow for wages, $w_{i t}$, consumer prices, $P_{c i t}$, and the world interest rate, $q_{t}$, all to vary over time (wages and consumer prices also vary across countries). Second, I include time- and country-specific distortionary taxes to international financial inflows and to labor income. Tax revenue in each country-year is rebated, in lump sum, back to the household through transfers, $T_{i t}$. The representative household solves the following problem:

$$
\begin{aligned}
\max _{C_{i t}, A_{i t+1}, L_{i t}} & \sum_{t=1}^{\infty} \beta \psi_{i t} N_{i t}\left(\ln \left(\frac{C_{i t}}{N_{i t}}\right)+\zeta_{i t} \frac{\left(1-\frac{L_{i t}}{N_{i t}}\right)^{1-1 / \phi}}{1-1 / \phi}\right) \\
\text { s.t. } & P_{i t}^{c} C_{i t}+\mathcal{A}_{i t+1}=w_{i t} L_{i t}\left(1-\tau_{i t}^{L}\right)+\left(1+q_{t}\right) \mathcal{A}_{i t}\left(1-\tau_{i t}^{\mathcal{A}}\right)+T_{i t}
\end{aligned}
$$

The two key Euler equations characterizing the household's decisions are:

$$
\begin{aligned}
\frac{C_{i t+1} / N_{i t+1}}{C_{i t} / N_{i t}} & =\beta \underbrace{\left(\frac{\psi_{i t+1}}{\psi_{i t}}\right)\left(1-\tau_{i t+1}^{\mathcal{A}}\right)}_{\omega_{i t}^{\mathcal{A}}}\left(\frac{1+q_{t+1}}{P_{i t+1}^{c} / P_{i t}^{c}}\right), \\
1-\frac{L_{i t}}{N_{i t}} & =\underbrace{\left(\zeta_{i t}\right)^{\phi}\left(1-\tau_{i t}^{L}\right)^{-\phi}}_{\omega_{i t}^{L}}\left(\frac{w_{i t}}{P_{i t}^{c}}\right)^{-\phi}\left(\frac{C_{i t}}{N_{i t}}\right)^{\phi} .
\end{aligned}
$$

The presence of preference shocks and distortions drives a wedge between per-capita consumption growth and the discounted real interest rate. The "saving wedge", defined as $\omega_{i t}^{\mathcal{A}}=\left(\frac{\psi_{i t+1}}{\psi_{i t}}\right)\left(1-\tau_{i t+1}^{\mathcal{A}}\right)$, captures the effect of both demographic forces (through preference shocks) and distortions on international bonds $5^{5}$ The "labor wedge", defined as $\omega_{i t}^{L}=\left(\zeta_{i t}\right)^{\phi}\left(1-\tau_{i t}^{L}\right)^{-\phi}$, captures the effects of both demographics (again, through preference shocks) and distortions on labor income.

Two remarks are in order in regarding the saving distortion. First, since the model tracks cross-country financial flows in net terms, the distortion symmetrically captures taxes on both inflows and outflows. Second, since the distortion is applied to both the stock, $\mathcal{A}$, and the flow payment, $q \mathcal{A}$, it captures both directions of the implicit gross flow: the capital outflow (purchase of foreign bond) and ensuing capital inflow (bond maturity).

The presence of distortions allows the theory to rationalize the data without placing all of the burden on the preference shocks. Later on in the paper, I consider a full general

\footnotetext{
${ }^{5}$ This is essentially the same wedge measured in Gourinchas and Jeanne (2013), although that paper does not identify what factors explain variation in the wedge. Saving wedges are also commonly used in trade models in order to help explain observed trade imbalances (see Kehoe, Ruhl, and Steinberg, 2018, Eaton, Kortum, Neiman, and Romalis, 2016).
} 
equilibrium model that incorporates additional features, such as bilateral trade across countries, investment in physical capital, and other supply-side features that collectively account the evolution of consumption, employment, wages, prices, interest rates, and other objects. None of these additional features affects the measurement of preference shocks or distortions.

Backing out saving and labor wedges The two wedges can be recovered from readily available data, given a couple of preference parameters. The discount rate is set to $\beta=0.96$ and the Frisch elasticity of labor supply is set to $\phi=2$, based on Peterman (2016).

The saving wedge is backed out as a residual from equation (7) by using data on a riskfree interest rate, consumer price growth, and per-capita consumption growth. The interest rate is the annual, nominal yield on the 10-year U.S. Treasury note. Consumption - sum of both private and public - is measured as gross domestic product (GDP) minus investment expenditures minus net exports, all divided by the consumption price level. The consumption price level is measured in 2011 U.S. dollars at current purchasing power parities (PPP).

The labor wedge is backed out as a residual from equation (8) using data on wages, consumer prices, employment, and consumption. The wage rate, $w_{i t}$, is defined as GDP times labor's share in GDP divided by the number of workers engaged. Appendix A provides more details on the data sources and manipulation.

Previous wedge accounting exercises attribute the entirety of the saving and labor wedges to the distortions (see Ohanian, Restrepo-Echavarria, and Wright, 2018). My view is that some of the variation in the wedges is "predictable and efficient" in the sense that it is driven by demographic forces. The remainder of the wedges are due to various distortions in the economy as well as model misspecification. Next I interact the calibrated wedges with demographic data to isolate the variation due to demographics.

Decomposing wedges Each wedge is defined as the product of a demographic component (preference shock) and a distortionary component: $\omega_{i t}^{\mathcal{A}}=\left(\frac{\psi_{i t+1}}{\psi_{i t}}\right)\left(1-\tau_{i t+1}^{\mathcal{A}}\right)$ and $\omega_{i t}^{L}=\left(\zeta_{i t}\right)^{\phi}\left(1-\tau_{i t}^{L}\right)^{-\phi}$. To take this to the data, I assume that each preference shock is a function of the age distribution: $\ln \left(\frac{\psi_{i t+1}}{\psi_{i t}}\right)=\mu^{\mathcal{A}} \times \mathbf{s}_{i t}$ and $\ln \left(\left(\zeta_{i t}\right)^{\phi}\right)=\mu^{L} \times \mathbf{s}_{i t}$. The variable $\mathbf{s}_{i t}=\left(s_{i t}^{15-64}, s_{i t}^{65+}\right)$ includes the share of the population aged 15-64 (working age share, using the World Bank's definition) and the share of the population aged 65 and up (retired age share) 6 The retired age share informs about saving behavior beyond the working age share

\footnotetext{
${ }^{6}$ I differentiate youth and retirees as Higgins (1998) offers evidence that increases in both youth and old-age dependency ratios individually correlate with lower saving rates.
} 
alone, since the working age share can decrease for two reasons. One being an increase in the share of individuals under 15 years old indicating a more youthful population. The other being an increase in the retired age share, indicating an aging population. Armed with these assumptions, I decompose each wedge using OLS:

$$
\begin{aligned}
& \ln \left(\omega_{i t}^{\mathcal{A}}\right)=\underbrace{\mu^{\mathcal{A}} \times \mathbf{s}_{i t}}_{\ln \left(\frac{\psi_{i t+1}}{\psi_{i t}}\right)}+\underbrace{\gamma_{i}^{\mathcal{A}}+\kappa_{t}^{\mathcal{A}}+\varepsilon_{i t}^{\mathcal{A}}}_{\ln \left(1-\tau_{i t+1}^{\mathcal{A}}\right)}, \\
& \ln \left(\omega_{i t}^{L}\right)=\underbrace{\mu^{L} \times \mathbf{s}_{i t}}_{\phi \ln \left(\zeta_{i t}\right)}+\underbrace{\gamma_{i}^{L}+\kappa_{t}^{L}+\varepsilon_{i t}^{L}}_{-\phi \ln \left(1-\tau_{i t}^{L}\right)} .
\end{aligned}
$$

Estimates from equations (9) and (10) are reported in Table 11. These estimates make use of unbalanced panels of 166 countries from 1960-2013 for the saving wedge (8,964 observations), and 127 countries from 1950-2014 for the labor wedge (8,255 observations).

Table 1: Estimated elasticity of wedges w.r.t. the age distribution

\begin{tabular}{ccccc}
\hline \hline & \multicolumn{2}{c}{ Right-hand side variable } & & \\
Left-hand side variable & $s_{i t}^{15-64}$ & $s_{i t}^{65+}$ & $R^{2}$ & $\#$ Obs. \\
\cline { 2 - 5 } Saving wedge: $\omega_{i t}^{\mathcal{A}}$ & $0.089^{\star \star \star}$ & 0.003 & 0.22 & 8,964 \\
& $(0.030)$ & $(0.010)$ & & \\
Labor wedge: $\omega_{i t}^{L}$ & $-2.234^{\star \star \star}$ & $-0.196^{\star \star \star}$ & 0.80 & 8,255 \\
& $(0.091)$ & $(0.028)$ & & \\
\hline
\end{tabular}

Notes: The estimates are based on OLS regressions using equation (9) and (10) with $\mathbf{s}_{i t}=\left(s_{i t}^{15-64}, s_{i t}^{65+}\right)$. Standard errors are in parentheses and ${ }^{\star \star}$ indicates statistical significance at the $95 \%$ level. Data availability limit the estimation to unbalanced panels of 166 countries from 1960-2013 for the saving wedge, and 127 countries from 1950-2014 for the labor wedge.

For the saving wedge, the coefficient on the working age share is significantly positive, reflecting the fact that working age individuals tend to save more than young individuals (under the age of 15). The coefficient on the retired age share is statistically indistinguishable from zero. The $R^{2}$ indicates that the age distribution, plus country and time fixed effects, accounts for almost one quarter of the overall variation in the saving wedge. This is not trivial particularly because the saving wedges fluctuate at a high frequency and are not perfectly correlated across countries, whereas demographics exhibit very low frequency variation.

For the labor wedge, the coefficient on the working age share is significantly negative, reflecting the fact that working age individuals tend to work more (have lower marginal utility of leisure) than young individuals. The coefficient on the retired age share is also 
negative, reflecting a non-trivial share of retired age individuals engaged in the workforce, compared to the share of young individuals that are engaged.

Figure 2 plots each wedge decomposed into its demographic and distortionary components for a sub-sample of countries. The sub-sample includes a balanced panel of 27 countries plus a rest-of-world aggregate from 1970-2014, which is the same sample of countries used in the quantitative analysis later in the paper.

Figure 2: Decomposition of calibrated wedges

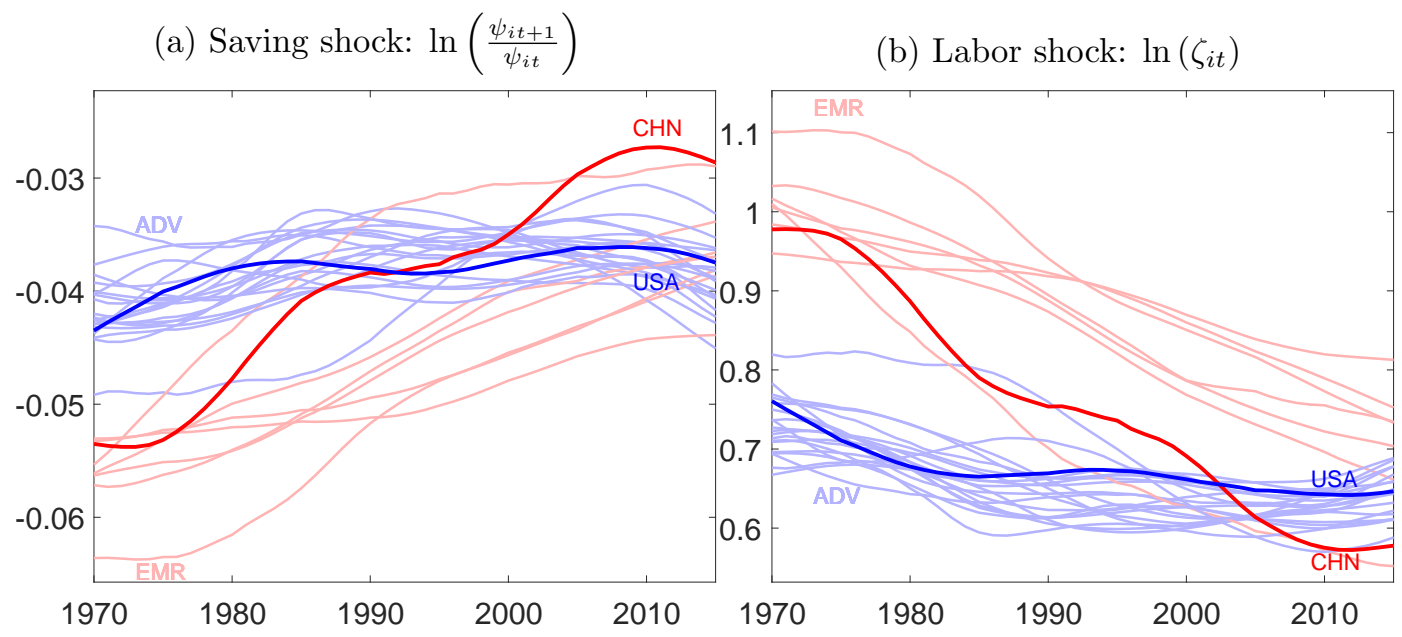

(c) Saving distortion: $\ln \left(1-\tau_{i t+1}^{\mathcal{A}}\right)$

(d) Labor distortion: $\ln \left(1-\tau_{i t}^{L}\right)$

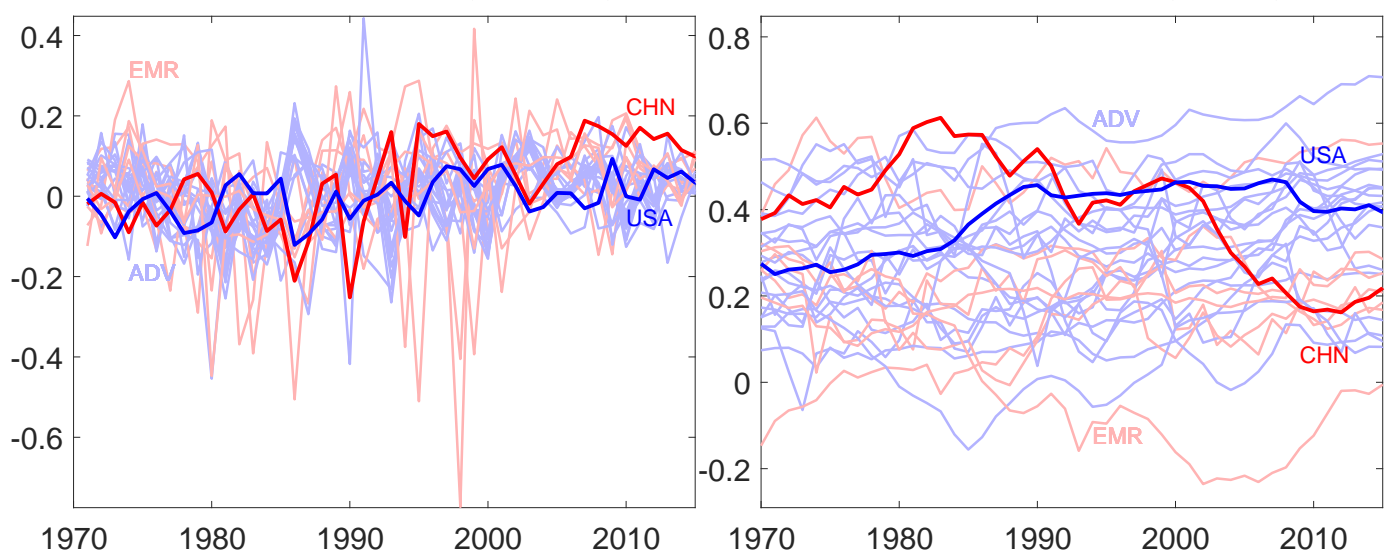

Notes: The log saving wedge is defined as $\ln \left(\omega_{i t}^{\mathcal{A}}\right)=\ln \left(\frac{\psi_{i t+1}}{\psi_{i t}}\right)+\ln \left(1-\tau_{i t+1}^{\mathcal{A}}\right)$ and the $\log$ labor wedge is defined as $\ln \left(\omega_{i t}^{L}\right)=\phi \ln \left(\zeta_{i t}\right)-\phi \ln \left(1-\tau_{i t}^{L}\right)$. Emerging economies (EMR) in red include Brazil, China, India, Indonesia, South Korea, Mexico, Turkey, and the rest-of-world aggregate. Advanced economies (ADV) in blue include the remaining 20 countries. 
For both the saving wedge and the labor wedge, there is an underlying time trend that co-moves with the age distribution. As a result, the preference shocks exhibit very low frequency variation reflecting the underlying demographic trends (see Figures $2 \mathrm{a}$ and $2 \mathrm{~b}$ ).

The general upward trend in the saving wedge experienced by most countries reflects increased population aging as youth enter working age life. Notably, the saving shock in China is quite low compared to that of the U.S. in 1970, but increases much more rapidly over time, and surpassing that of the United States in the early 1990s. The early 1990s coincides with the beginning of China's demographic window.

The general downward trend in the labor wedge experienced by most countries reflects increased population aging as youth enter working age life. Specifically, the labor shock begins at a high level in China, declining sharply thereafter, and reaching a level lower than almost every other country by 2014 .

The distortionary component of each wedge exhibits much higher frequency variation over time (see Figures $2 \mathrm{c}$ and 2d). The distortionary component is comprised of the sum of the country-fixed effect, the time-fixed effect, and the residual.

With regards to the saving wedge, the distortionary component captures factors that affect the consumption-saving trade-off such as capital controls, monetary policy, fiscal policy, social safety nets, currency risk, and general economic uncertainty, in addition to model misspecification. For instance, prior to 1990 the saving distortion in China generally switches rank back and forth with that in the United States. After 1990, the distortionary component in China remains elevated compared to that in the United States. This may partly capture capital controls imposed by China, particularly on outflows of financial capital as indicated by large $\left(1-\tau^{\mathcal{A}}\right)$. One example of misspecification may be un-modeled habits.7

With regards to the labor wedge, distortions capture labor income taxation, labor market laws and regulations, female labor force participation, and other non-modeled factors. Prior to 1980, the labor distortion in China is relatively high- $\left(1-\tau^{L}\right)$ is low-but declines steadily thereafter. This perhaps captures the ongoing marketization of the Chinese economy, coupled with labor market deregulation in the form of migration from rural areas to cities.

The preference shocks empirically connect observed demographics to the theory. In order to connect with trade imbalances in a general equilibrium setting, the model needs more structure on the supply side. Since a country's trade imbalance is the difference between its saving and investment, the next section incorporates bilateral trade and capital formation.

\footnotetext{
${ }^{7}$ Carroll, Overland, and Weil (2000) posit that habits can account for the fact that a boom income is not immediately met with a boom in consumption.
} 


\section{General equilibrium model}

The general equilibrium model builds on the setup from Section 2.2 by incorporating a rich supply side in which prices are determined globally.

Technology There is a unit interval of potentially tradable varieties, $v \in[0,1]$. All varieties are combined symmetrically to construct a composite good:

$$
Q_{i t}=\left[\int_{0}^{1} q_{i t}(v)^{1-1 / \eta} d v\right]^{\eta /(\eta-1)},
$$

where $\eta$ is the elasticity of substitution between any two varieties. The term $q_{i t}(v)$ is the quantity of variety $v$ used to construct the composite good in country $i$ at time $t$.

The composite good is nontradable, and is used to satisfy final consumption demand, final investment demand, and intermediate input demand. One unit of the composite good can be transformed into $\chi_{i t}^{c}$ units of consumption, into $\chi_{i t}^{x}$ units of investment, or into one unit of the intermediate input. These transformation costs pin down relative prices and are needed to reconcile the Lucas (1990) paradox.8

Country $i$ can produce variety $v$ using capital, labor, and intermediates:

$$
Y_{i t}(v)=z_{i t}(v)\left(A_{i t} K_{i t}(v)^{\alpha} L_{i t}(v)^{1-\alpha}\right)^{\nu_{i t}} M_{i t}(v)^{1-\nu_{i t}} .
$$

The term $M_{i t}(v)$ is the quantity of the composite good used as an input to produce $Y_{i t}(v)$ units of variety $v$, while $K_{i t}(v)$ and $L_{i t}(v)$ are the quantities of capital and labor used.

The parameter $\nu_{i t}$ denotes the share of value added in total output in country $i$ at time $t$, while $\alpha$ denotes capital's share in value added. This parameter provides flexibility for the model to simultaneously reconcile gross trade flows and value added output.

The term $A_{i t}$ denotes country $i$ 's value-added productivity at time $t$ while the term $z_{i t}(v)$ is country $i$ 's idiosyncratic productivity draw for producing variety $v$ at time $t$, which scales gross output. Idiosyncratic productivity in each country is drawn independently from a Fréchet distribution with c.d.f. $F(z)=\exp \left(-z^{-\theta}\right)$.

Trade Each country sources each variety from its least-cost supplier. International trade is subject to physical iceberg costs. At time $t$, country $i$ must purchase $d_{i j t} \geq 1$ units

\footnotetext{
8 Caselli and Feyrer (2007) argue that differences in the relative price of investment help rationalize why capital does not flow from rich to poor countries.
} 
of any intermediate variety from country $j$ in order for one unit to arrive; $d_{i j t}-1$ units melt away in transit. As a normalization I assume that $d_{i i t}=1$ for all $i$ and $t$.

Endowments and demographics Initially each country is endowed with a stock of capital, $K_{i 1}$, and a NFA position, $\mathcal{A}_{i 1}$. In each period population is given exogenously by $N_{i t}$. The model does not explicitly include heterogeneity in the population with respect to age. Instead, the age distribution is manifested in certain "preference shocks" described below.

Preferences Lifetime utility is defined exactly as in section 2.2 .

$$
\sum_{t=1}^{\infty} \beta^{t-1} \psi_{i t} N_{i t}\left(\ln \left(\frac{C_{i t}}{N_{i t}}\right)+\zeta_{i t} \frac{\left(1-\frac{L_{i t}}{N_{i t}}\right)^{1-1 / \phi}}{1-1 / \phi}\right) .
$$

The parameter $\psi_{i t}$ is a shock to the marginal utility of consumption country $i$ at time $t$, meaning that $\frac{\psi_{i t+1}}{\psi_{i t}}$ is the "saving shock" in period $t$. The term $\zeta_{i t}$ is the "labor shock".

Net-foreign asset accumulation The representative household enters period $t$ with NFA position $\mathcal{A}_{i t}$. If $\mathcal{A}_{i t}<0$ then the household has a net debt position. It is augmented by net purchases of one-period bonds (the current account balance), $\mathcal{B}_{i t}$. With $\mathcal{A}_{i 1}$ given,

$$
\mathcal{A}_{i t+1}=\mathcal{A}_{i t}+\mathcal{B}_{i t}
$$

Capital accumulation The household enters period $t$ with $K_{i t}$ units of capital. Investment, $X_{i t}$, adds to the stock of capital subject to an adjustment cost and depreciation. With $K_{i 1}>0$ given, capital accumulates according to

$$
K_{i t+1}=(1-\delta) K_{i t}+\delta^{1-\lambda} X_{i t}^{\lambda} K_{i t}^{1-\lambda}
$$

The depreciation rate, $\delta$, and the adjustment cost elasticity, $\lambda$, are constant both across countries and over time. The term $\delta^{1-\lambda}$ ensures that there are no adjustment costs to replace depreciated capital; for instance, in a steady state, $X^{\star}=\delta K^{\star}$. The adjustment cost implies that the return to capital investment depends on the quantity of investment. This guarantees a unique, optimal portfolio choice with respect to capital investment and bond purchases, and also ensures that gross capital formation is positive. 
Budget constraint Capital and labor are compensated at the rates $r_{i t}$ and $w_{i t}$, respectively, and are subject to distortionary taxes, $\tau_{i t}^{L}$ and $\tau_{i t}^{K}$. Current investment expenditures are tax deductible. $9^{9}$ The world interest rate on bonds at time $t$ is denoted by $q_{t}$ and crossborder financial flows are subject to a distortionary tax, $\tau_{i t}^{\mathcal{A}}$. All tax revenue is returned in lump sum to the household, $T_{i t}$.

With consumption and investment prices denoted by $P_{i t}^{c}$ and $P_{i t}^{x}$, respectively, the budget constraint in each period is given by

$$
P_{i t}^{c} C_{i t}+\mathcal{A}_{i t+1}=\left(r_{i t} K_{i t}-P_{i t}^{x} X_{i t}\right)\left(1-\tau_{i t}^{K}\right)+w_{i t} L_{i}\left(1-\tau_{i t}^{L}\right)+\left(1+q_{t}\right) \mathcal{A}_{i t}\left(1-\tau_{i t}^{\mathcal{A}}\right)+T_{i t} .
$$

\subsection{Equilibrium}

A competitive equilibrium satisfies the following conditions: (i) taking prices as given, the representative household in each country maximizes its lifetime utility subject to its budget constraint and technologies for accumulating physical capital and assets, (ii) taking prices as given, firms maximize profits subject to the available technologies, (iii) intermediate varieties are purchased from their lowest-cost provider, and (iv) markets clear. At each point in time world GDP is the numéraire: $\sum_{i=1}^{I} r_{i t} K_{i t}+w_{i t} L_{i}=1$. That is, all prices are expressed in units of current world GDP. Appendix B describes the equilibrium conditions in more detail.

Remark on general equilibrium effects The demand-side shocks were discussed in detail in Section 2.2 in the context of two key Euler equations:

$$
\begin{aligned}
\frac{C_{i t+1} / N_{i t+1}}{C_{i t} / N_{i t}} & =\beta\left(\frac{\psi_{i t+1}}{\psi_{i t}}\right)\left(1-\tau_{i t+1}^{\mathcal{A}}\right)\left(\frac{1+q_{t+1}}{P_{i t+1}^{c} / P_{i t}^{c}}\right), \\
1-\frac{L_{i t}}{N_{i t}} & =\left(\zeta_{i t}\right)^{\phi}\left(1-\tau_{i t}^{L}\right)^{-\phi}\left(\frac{w_{i t}}{P_{i t}^{c}}\right)^{-\phi}\left(\frac{C_{i t}}{N_{i t}}\right)^{\phi} .
\end{aligned}
$$

Demographics, operating through preference shocks, influence external imbalances (i) directly through the consumption-saving trade-off and (ii) indirectly through labor supply as a country's ability to finance existing liabilities depends on its productive capacity. These Euler equations also indicate that saving and labor supply depend on various prices.

In a general equilibrium setting, prices are also indirectly influenced by the preference shocks and distortions to saving and labor income, thereby confounding the effects on saving and labor supply. In addition, other supply-side forces influence the evolution of prices.

\footnotetext{
${ }^{9}$ This assumption brings tractability by making the distortion separable from the gross return on capital.
} 
For one, the overall price level in a country depends on technologies across the world, subject to the trade costs with said countries:

$$
P_{i t}=\gamma\left(\sum_{j=1}^{I}\left(\left(A_{j t}\right)^{-\nu_{j t}} u_{j t} d_{i j t}\right)^{-\theta}\right)^{-\frac{1}{\theta}}
$$

where $u_{j t}=\left(\frac{r_{j t}}{\alpha \nu_{j t}}\right)^{\alpha \nu_{j t}}\left(\frac{w_{j t}}{(1-\alpha) \nu_{j t}}\right)^{(1-\alpha) \nu_{i t}}\left(\frac{P_{j t}}{1-\nu_{j t}}\right)^{1-\nu_{j t}}$ is the unit cost of production. Productivity growth or declining trade costs result in a lower price level, thereby raising the real interest rate, $\frac{1+q_{t+1}}{P_{i t+1}^{c} / P_{i t}^{c}}$. In turn, a country with faster declining prices due to technology or trade costs would attract foreign investment and experience faster consumption growth, growing real wages, and increased labor supply. The conversion costs, $\chi_{i t}^{c}$ and $\chi_{i t}^{x}$, also impact imbalances by governing rate of transforming of tradables into consumption and investment.

In addition, investment distortions affect the real interest rate through a no arbitrage condition: Households must be indifferent between purchasing a unit of investment and purchasing a bond, so that the after-tax returns are equalized:

$$
\left(1-\tau_{i t+1}^{\mathcal{A}}\right)\left(1+q_{t+1}\right)=\left(\frac{\frac{r_{i t+1}}{P_{i t+1}^{x}}-\Phi_{2}\left(K_{i t+2}, K_{i t+1}\right)}{\Phi_{1}\left(K_{i t+1}, K_{i t}\right)}\right)\left(\frac{P_{i t+1}^{x}}{P_{i t}^{x}}\right)\left(\frac{1-\tau_{i t+1}^{K}}{1-\tau_{i t}^{K}}\right),
$$

where $X \equiv \Phi\left(K^{\prime}, K\right)=\delta^{1-1 / \lambda}\left(\frac{K^{\prime}}{K}-(1-\delta)\right)^{1 / \lambda} K$ denotes investment, and $\Phi_{1}$ and $\Phi_{2}$ denote the derivatives with respect to the first and second arguments, respectively 10

As investment distortions fall, the real rate of return on capital investment rises implying a higher real interest rate and attracting foreign financial flows. The rental rate of capital also depends on the labor supply relative to the stock of capital, and therefore on the age distribution, and thus influences financial flows and external imbalances across countries.

\section{Calibration}

The model is applied to 28 countries (27 individual countries plus a rest-of-world aggregate) from 1970-2060. Data from 1970-2014 are realized, while data from 2015-2060 are based on projections. Incorporating projections serves two purposes. First, it imposes the terminal conditions as of 2060, far enough beyond 1970-2014, which is the period of interest. Second, it provides external discipline to the agents expectations in formulating saving decisions prior

\footnotetext{
${ }^{10}$ With $\lambda=1$, there is no adjustment cost and capital depreciates linearly: $\Phi_{1}=1$ and $\Phi_{2}=(\delta-1)$.
} 
to 2014. Appendix A describes the data and lists the countries with their 3-digit ISO codes.

The calibration involves two parts. The first part assigns values to the common parameters: $(\beta, \phi, \alpha, \delta, \lambda, \theta, \eta)$. These are taken from existing literature.

The second part assigns values to the country-specific and time-varying parameters: $\left(K_{i 1}, \mathcal{A}_{i 1},\left\{N_{i t}, \chi_{i t}^{c}, \chi_{i t}^{x}, \nu_{i t}, \psi_{i t}, \zeta_{i t}, \tau_{i t}^{K}, \tau_{i t}^{L}, \tau_{i t}^{\mathcal{A}}, d_{i j t}, A_{i t}\right\}_{t=1}^{T}\right)$ for all $(i, j)$. Some of the countryspecific parameters are observable. For the ones that are not observable, I invert structural equations from the model and link them with data. That is, these parameters are inferred to rationalize both the observed and projected data as a solution to a perfect foresight equilibrium. The data targets, roughly in order of how they map into the model parameters, are (i) initial stock of capital, (ii) initial NFA position, (iii) population, (iv) price level of consumption using PPP exchange rates, (v) price level of investment using PPP exchange rates, (vi) ratio of value added to gross output, (vii) real consumption growth, (viii) ratio of employment to population, (ix) real investment, (x) bilateral trade flows, and (xi) price level of tradables using PPP exchange rates. The calibration ensures internal consistency with national accounts in every country-year 11

Common parameters The values for the common parameters are reported in Table 2. As in Section 2.2, I set $\beta=0.96$ and $\phi=2$.

Capital's share in value added is set to 0.33 , based on evidence in Gollin (2002). In line with the literature, I set the depreciation rate for capital to $\delta=0.06$. The adjustment cost elasticity is set to $\lambda=0.76$, which is the midpoint between 0.52 and 1 . The value 0.52 corresponds to the median value used by Eaton, Kortum, Neiman, and Romalis (2016) who work with quarterly data $(\lambda=1$ corresponds to no adjustment costs).

I set the trade elasticity to $\theta=4$ as in Simonovska and Waugh (2014). The parameter $\eta$ plays no role in the model other than satisfying $1+\frac{1}{\theta}(1-\eta)>0$; I set $\eta=2$.

Initial conditions For each country the initial stock of capital, $K_{i 1}$, is taken directly from the data in 1970, while the initial net-foreign asset position is set to $\mathcal{A}_{i 1}=0$.

Population, value added shares, and relative prices Population, $N_{i t}$, is observable. The parameter $\nu_{i t}$ is defined as the ratio of aggregate value added to gross production,

\footnotetext{
${ }^{11}$ Note that there are 13 time-varying parameters and only 11 independent data series. The national accounts data identifies the saving wedge, which is the product of the saving shock and the saving distortion, as well as the labor wedge, which is the product of the labor shock and the labor distortion. Section 2.2 separately identifies the preference shocks from the distortions by utilizing information on demographics and imposing reduced-form restrictions encapsulated by the microfoundations of the OLG economy.
} 
Table 2: Common parameters

\begin{tabular}{clc}
\hline \hline$\beta$ & Annual discount factor & 0.96 \\
$\phi$ & Elasticity of labor supply & 2 \\
$\alpha$ & Capital's share in value added & 0.33 \\
$\delta$ & Annual depreciation rate for stock of capital & 0.06 \\
$\lambda$ & Adjustment cost elasticity & 0.76 \\
$\theta$ & Trade elasticity & 4 \\
$\eta$ & Elasticity of substitution between varieties & 2 \\
\hline
\end{tabular}

and is constructed as such. The (inverse) relative price of consumption, $\chi_{i t}^{c}$, is computed as the price of intermediates relative to consumption. Similarly, $\chi_{i t}^{x}$ is the price of intermediates relative to investment. Prices of intermediates, consumption, and investment are observable.

$$
\nu_{i t}=\frac{r_{i t} K_{i t}+w_{i t} L_{i t}}{r_{i t} K_{i t}+w_{i t} L_{i t}+P_{i t} M_{i t}}=\frac{\operatorname{GDP}_{i t}}{\text { Gross production }_{i t}}, \quad \chi_{i t}^{c}=\frac{P_{i t}}{P_{i t}^{c}}, \quad \chi_{i t}^{x}=\frac{P_{i t}}{P_{i t}^{x}}
$$

Preference shocks, saving distortions, and labor distortions The wedges, $\omega_{i t}^{\mathcal{A}}=$ $\left(\frac{\psi_{i t+1}}{\psi_{i t}}\right)\left(1-\tau_{i t+1}^{\mathcal{A}}\right)$ and $\omega_{i t}^{L}=\left(\zeta_{i t}\right)^{\phi}\left(1-\tau_{i t}^{L}\right)^{-\phi}$, are exactly those computed from equations (7) and 80 in Section 2.2. From these wedges, the preference shocks, $\left(\frac{\psi_{i t+1}}{\psi_{i t}}, \zeta_{i t}\right)$, and the distortions, $\left(\tau_{i t}^{\mathcal{A}}, \tau_{i t}^{L}\right)$, are those recovered from regressions $(9)$ and $(10)$ in Section 2.2 .

Investment distortions Without loss of generality, I initialize $\tau_{i 1}^{K}=0$. The remaining investment distortions require measurements of the capital stock in every period. Given capital stocks in period $1, K_{i 1}$, and data on investment in physical capital, $X_{i t}$, I construct the sequence of capital stocks iteratively using $K_{i t+1}=(1-\delta) K_{i t}+\delta^{1-\lambda} X_{i t}^{\lambda} K_{i t}^{1-\lambda}$.

To ease notation, define $\Phi\left(K^{\prime}, K\right) \equiv X \equiv \delta^{\frac{\lambda-1}{\lambda}}\left(\frac{K^{\prime}}{K}-(1-\delta)\right)^{\frac{1}{\lambda}} K$, and let $\Phi_{1}$ and $\Phi_{2}$ denote the partial derivatives with respect to the first and second arguments respectively. Given the constructed sequence of capital stocks, I recover $\tau_{i t+1}^{K}$ iteratively using the Euler equation for investment in physical capital:

$$
\frac{C_{i t+1} / N_{i t+1}}{C_{i t} / N_{i t}}=\beta\left(\frac{\psi_{i t+1}}{\psi_{i t}}\right)\left(\frac{\frac{r_{i t+1}}{P_{i t+1}^{c}}-\left(\frac{P_{i t+1}^{x}}{P_{i t+1}^{c}}\right) \Phi_{2}\left(K_{i t+2}, K_{i t+1}\right)}{\left(\frac{P_{i t}^{x}}{P_{i t}^{c}}\right) \Phi_{1}\left(K_{i t+1}, K_{i t}\right)}\right)\left(\frac{1-\tau_{i t+1}^{K}}{1-\tau_{i t}^{K}}\right) .
$$

Prices for consumption and investment come from the national accounts data, as does percapita consumption. The rental rate for capital, defined according to the theory, is constructed as: $r_{i t}=\left(\frac{\alpha}{1-\alpha}\right)\left(\frac{w_{i t} L_{i t}}{K_{i t}}\right)$. 
Trade costs The trade cost for any given country pair is computed using data on prices and bilateral trade shares using the following structural equation:

$$
\frac{\pi_{i j t}}{\pi_{i i t}}=\left(\frac{P_{j t}}{P_{i t}}\right)^{-\theta} d_{i j t}^{-\theta}
$$

where $\pi_{i j t}$ is the share of country $i$ 's absorption that is sourced from country $j$ and $P_{i t}$ is the price of tradables in country $i$. I set $d_{i j t}=10^{8}$ for observations in which $\pi_{i j t}=0$ and set $d_{i j t}=1$ if the inferred value is less than 1 . As a normalization, $d_{i i t}=1$.

Productivity I back out productivity, $A_{i t}$, using price data and home trade shares,

$$
P_{i t}=\left(\frac{\gamma\left(\pi_{i i t}\right)^{\frac{1}{\theta}}}{\left(A_{i t}\right)^{\nu_{i t}}}\right)\left(\frac{r_{i t}}{\alpha \nu_{i t}}\right)^{\alpha \nu_{i t}}\left(\frac{w_{i t}}{(1-\alpha) \nu_{i t}}\right)^{(1-\alpha) \nu_{i t}}\left(\frac{P_{i t}}{1-\nu_{i t}}\right)^{1-\nu_{i t}}
$$

More simply, $P_{i t}=\frac{u_{i t}}{Z_{i t}}$, where $u_{i t}$ is the unit cost of an input bundle and $Z_{i t}=\left(\frac{\left(A_{i t}\right)^{\nu_{i t}}}{\gamma\left(\pi_{i i t}\right)^{\frac{1}{\theta}}}\right)$ is measured productivity of gross output. ${ }^{12}$

\subsection{Key drivers of trade flows}

As is well known, the Eaton-Kortum model of trade gives rise to a gravity structure whereby productivity and trade costs are the primary determinants of international trade patterns. These parameters therefore have direct implications for bilateral trade flows and, ultimately, aggregate trade imbalances. Figure 3 shows the paths for the calibrated fundamental productivity and bilateral trade costs, $\left(A_{i t}, d_{i t}\right)$.

Throughout most of the sample, most countries experienced growth in fundamental productivity (see Figure 3a). Note that this measure of productivity is not the same as TFP, which can also grow due to an expanding import share ${ }^{13}$ Still, there are differences in both the levels and rates of productivity growth across countries. For instance, China's rapid growth beginning in early 1990s is captured to a large extent by its catch up in productivity. The United States exhibited slightly lower productivity growth than other high-income countries. All else equal, these features give rise to relatively fast growing exports in China and relatively fast growing imports in the United States.

\footnotetext{
${ }^{12}$ The parameter $\gamma=\Gamma(1+(1-\eta) / \theta)^{1 /(1-\eta)}$ is a constant, where $\Gamma(\cdot)$ is the Gamma function.

${ }^{13}$ Measured TFP also accounts for an endogenous change in the home trade share: $\operatorname{TFP}_{i t} \propto A_{i t}\left(\pi_{i i t}\right)^{-\frac{1}{\theta_{\nu i t}}}$.
} 
Figure 3: Productivity and trade costs

(a) Productivity: $A_{i t}$

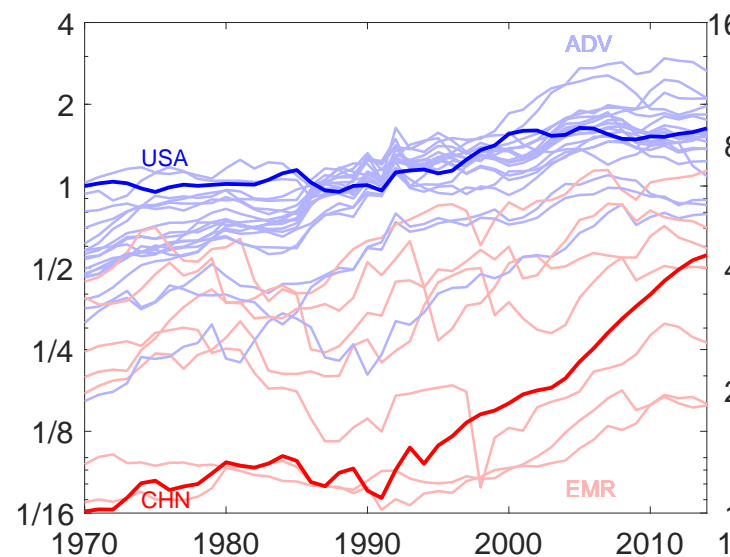

(b) Trade costs: $\left(d_{i j t}-1\right)$

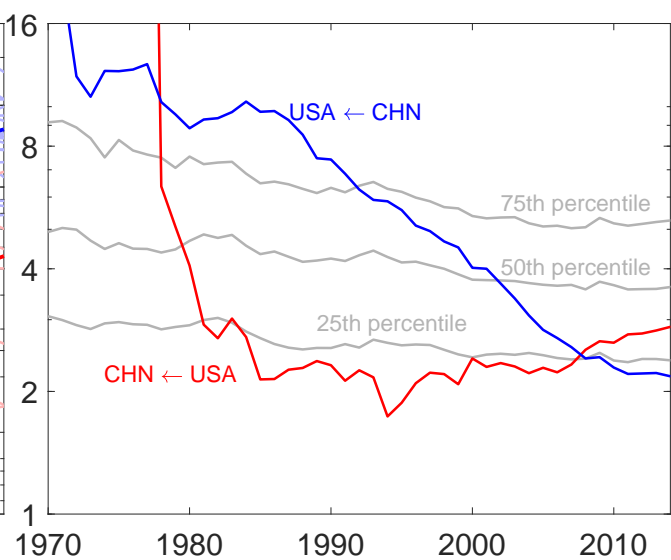

Notes: Productivity is shown relative to that of the United States in 1970. Trade cost percentiles are computed from the entire matrix of bilateral trade costs in each year, excluding the diagonal. Prior to 1978, China's are too large to include on the same scale, reflecting the negligible volume of international trade, particularly imports, taking place. Emerging economies (EMR) in red include Brazil, China, India, Indonesia, South Korea, Mexico, Turkey, and the rest-of-world aggregate. Advanced economies (ADV) in blue include the remaining 20 countries.

The levels of the calibrated trade costs are in line with most estimates in the literature that use gravity-based models (see Figure 3b). The trade costs decline over time, reflecting growing international trade volumes, partly due to tariff cuts and free trade agreements, in addition to improvements in shipping technology. Beyond a common trend of declining trade costs, there is substantial heterogeneity across countries. In particular, there is rapid decline in bilateral trade costs between China and the United States following China's economic reforms in 1978 under Deng Xiaoping. The trade costs prior to 1978 are too large to include on the same scale, reflecting the closedeness of China. The trade cost from China to the United States gradually declined ever since the 1980s. On the other hand, the trade cost from the United States to China declined rapidly for a few years after 1978, but remained fairly flat thereafter and, subsequently, mildly increased since the mid-1990s. Mechanically, the asymmetry in the bilateral cost between China and the United States since the 1990s captures the widening bilateral trade imbalance between the two countries. Economically, the asymmetry might partially capture Chinese policies aimed at keeping the Yuan "devalued" against the U.S. dollar, or other policies that favor exports by Chinese state-owned enterprises. 


\section{Quantitative analysis}

This section quantifies the importance of demographics, and other forces, in shaping the evolution of trade imbalances. This is done by evaluating counterfactual equilibria arising from counterfactual processes for preference shocks and other exogenous forces. Given the counterfactual processes for the shocks, I compute the dynamic equilibrium under perfect foresight from 1970-2060. Appendix C provides the details of the algorithm for solving for the transition, which builds on Ravikumar, Santacreu, and Sposi (2018) and Sposi (2012).

\subsection{The role of changes in the age distribution across the world}

In order to quantify the importance of differential changes in the age distribution across countries, this counterfactual assumes that every country's age distribution is constant from 1970-2060. I construct counterfactual preference shocks as

$$
\frac{\widetilde{\psi}_{i t+1}}{\widetilde{\psi}_{i t}}=\frac{\psi_{i 1971}}{\psi_{i 1970}}, \quad \widetilde{\zeta}_{i t}=\zeta_{i 1970}
$$

with $\widetilde{\psi}_{i 1970}=\psi_{i 1970}=1$, and hold all other parameters at their calibrated values.

Figure 4 illustrates, for every country, how trade imbalances compare in the counterfactual relative to the baseline. Specifically, the figure reports, for each country, the average ratio of net exports to GDP taken over 1970-2014: $\left(\frac{1}{45}\right) \sum_{1970}^{2014} \frac{N X_{i t}}{G D P_{i t}}$. There is a distinct difference between advanced and emerging economies. In advanced economies, where the working age share only slightly increased, or in some cases decreased, the ratio of net exports to GDP was higher in the counterfactual than in the baseline. The opposite is true in emerging economies where the working age share increased at much higher rates, and the ratios of net exports to GDP in the counterfactual were lower compared to the baseline.

Figure 5 illustrates the systematic relationship between changes in each country's working age share and the difference in its trade imbalances in the baseline relative to the counterfactual. The vertical axis is the difference in each country's average ratio of net exports to GDP in the baseline relative to the counterfactual: $\left(\frac{1}{45}\right) \sum_{t=1970}^{2014} \frac{N X_{i t}^{\text {base }}}{G D P_{i t}^{\text {bese }}}-\left(\frac{1}{45}\right) \sum_{t=1970}^{2014} \frac{N X_{i t}^{c f}}{G D P_{i t}^{c f}}$. The horizontal axis is the change in each country's working age share relative to that of the entire world: $\left(s_{i 2014}-s_{i 1970}\right)-\left(s_{W 2014}-s_{W 1970}\right)$. The slope of the best fit line is 0.31 , implying that a one percentage point increase in a country's working age share, relative to that of the world, generates about one-third percentage point increase in its net exports to GDP. 
Figure 4: Average ratio of net exports to GDP from 1970-2014

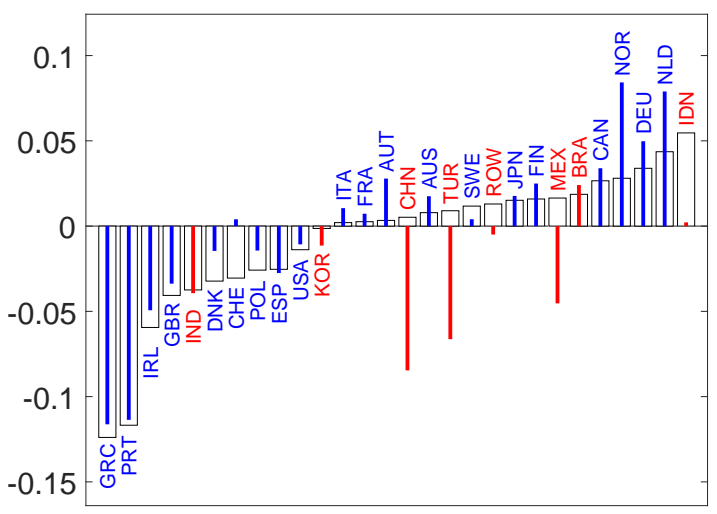

Notes: Average ratio of net exports to GDP from 1970-2014: $\left(\frac{1}{45}\right) \sum_{t=1970}^{2014} \frac{N X_{i t}}{G D P_{i t}}$. Bars refer to the baseline model. Lines refer to the counterfactual with every country's age distribution simultaneously fixed at 1970 levels. Emerging economies are in red and advanced economies, in blue.

Figure 5: Difference in average ratio of net exports to GDP from 1970-2014

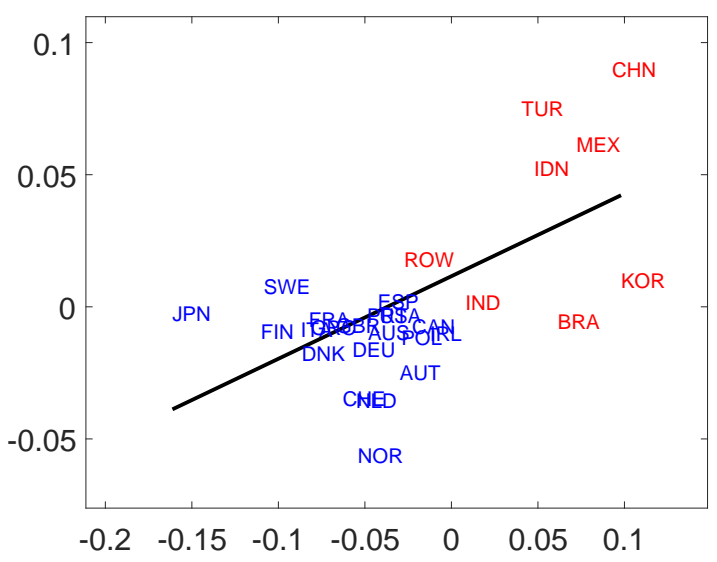

Notes: Vertical axis - Change in average ratio of net exports to GDP from 1970-2014:

$\left(\frac{1}{45}\right) \sum_{t=1970}^{2014} \frac{N X_{i t}^{\text {base }}}{G D P_{i t}^{\text {base }}}-\left(\frac{1}{45}\right) \sum_{t=1970}^{2014} \frac{N X_{i t}^{c f}}{G D P_{i t}^{c f}}$, where $c f$ denotes the counterfactual with every country's age distribution simultaneously fixed at 1970 levels and base refers to the baseline. Horizontal axis - Change in working age share relative to the world:

$\left(s_{i 2014}-s_{i 1970}\right)-\left(s_{W 2014}-s_{W 1970}\right)$. Emerging economies are in red and advanced economies, in blue.

The main takeaway is that differences in demographic trends between advanced and emerging economies induced a growing appetite for net-saving by emerging economies, resulting in lower net exports in advanced economies. As an example, consider a contrast 
between China and the United States. China experienced a rapid increase in its working age share from 1970 to 2014, while the United States experienced only a mild increase. Figure 6a shows that if age distributions were held constant in all countries, then China would have run a large trade deficit. Note that the counterfactual trade imbalance in China returns to surplus, and is almost the same as in the baseline, by 2014. This reflects the sharp shift in China's working age share going from a fast increase leading up to 2014, followed by a rapid projected decline after 2014.

Figure 6: Ratio of net exports to GDP from 1970-2014

(a) China

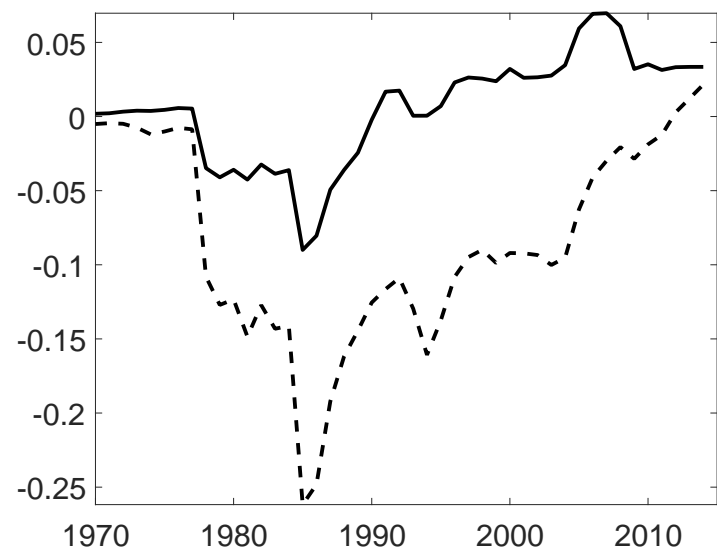

(b) United States

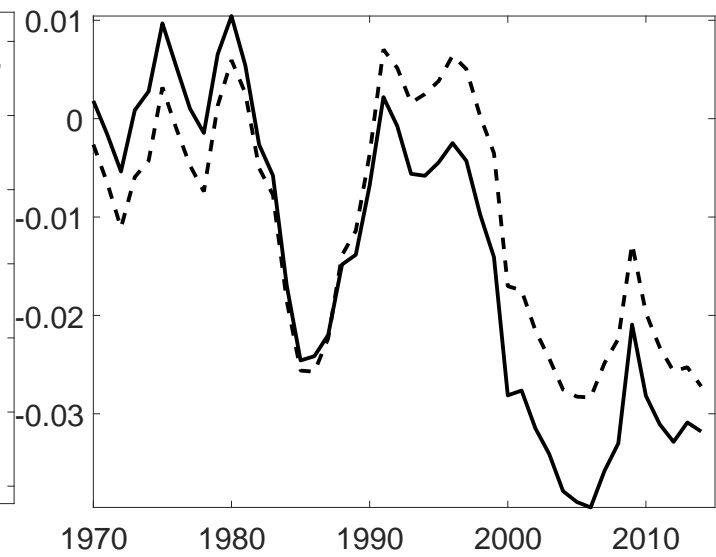

Notes: Solid lines refer to the baseline model. Dashed lines refer to the counterfactual with age distributions simultaneously held fixed at 1970 levels.

Figure 6b illustrates the path for the ratio of net exports to GDP in the United States. Not only is the ratio higher on average in the counterfactual compared to the baseline, but the ratio is also flatter over time. In particular, the counterfactual ratio is actually slightly lower than the baseline ratio from 1970-1985, but after 1990, the counterfactual ratio is permanently higher the baseline ratio. Put differently, the counterfactual ratio falls by only 2.4 percentage points between 1970 and 2014 (from $-0.3 \%$ to $-2.7 \%$ ) instead of falling by 3.4 percentage points (from $0.2 \%$ to $-3.2 \%$ ) in the baseline.

Figure 6 also illustrates that demographic-induced forces give rise to a persistent and gradual influence on trade imbalances. Higher frequency fluctuations are still present in the counterfactual as in the baseline. This finding generalizes that of Ferrero (2010) and Backus, Cooley, and Henriksen (2014). Ferrero (2010) demonstrates, in a two-country model of the United States and G6 countries, that demographics are responsible for the persistent increase 
in the U.S. trade deficit. Backus, Cooley, and Henriksen (2014) arrive at a similar conclusion in four-country model of China, Germany, and Japan, and the United States. The baseline and counterfactual trade imbalances for all countries are in Figure D.4 in Appendix D.

Demographic effects through two distinct channels Brooks (2003) argues a that a relatively fast-aging region will tend to save more in preparation for retirement, but at the same time investment demand will fall as the workforce shrinks. The following two counterfactuals isolate the individual importance of the saving shock and the labor shock induced by the same underlying demographic trends. The first imposes the counterfactual path for saving shocks, $\left\{\widetilde{\psi}_{i t}\right\}$ from equation 13 , holding all other parameters at their baseline values. The second imposes the counterfactual path for labor shocks, $\left\{\widetilde{\zeta}_{i t}\right\}$ from equation (13), holding all other parameters at their baseline values.

Figure 7 plots the average ratio of net exports to GDP from 1970-2014, $\left(\frac{1}{45}\right) \sum_{t=1970}^{2014} \frac{N X_{i t}}{G D P_{i t}}$, for both the baseline and each counterfactual. In particular, Figure $7 \mathrm{a}$ illsutrates the comparison for the counterfactual saving shocks, while Figure $7 \mathrm{~b}$ illustrates that for the counterfactual labor shocks. There are notable differences in each counterfactual with respect to the baseline, and also with respect to each other.

Figure 7: Average ratio of net exports to GDP from 1970-2014

(a) Frozen saving shocks

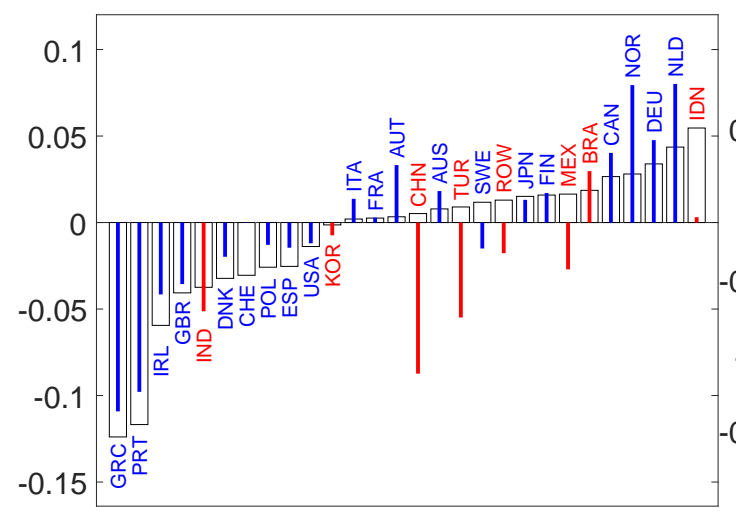

(b) Frozen labor shocks

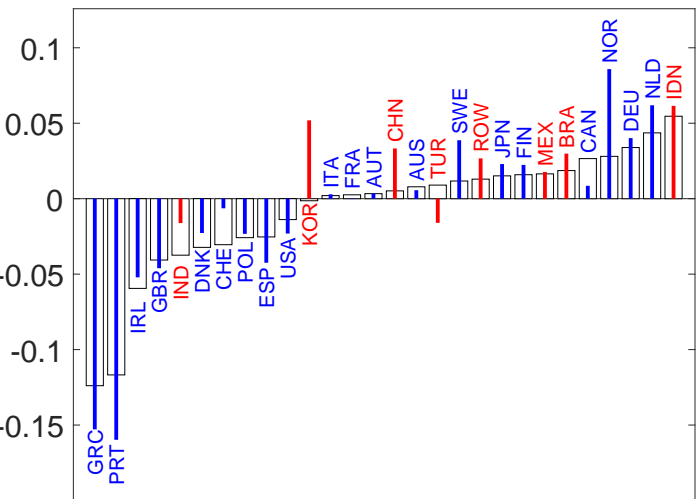

Notes: Average ratio of net exports to GDP from 1970-2014: $\left(\frac{1}{45}\right) \sum_{t=1970}^{2014} \frac{N X_{i t}}{G D P_{i t}}$. Bars refer to the baseline model. Lines refer to the counterfactual with preference shocks in every country simultaneously frozen at 1970 levels. Emerging economies are in red and advanced economies, in blue.

With counterfactual saving shocks, the United States accumulates a slightly smaller trade deficit compared to the data, while China accumulates a larger deficit. More generally, ad- 
vanced economies that experienced relatively slow increases, or even decreases, in the working age share from 1970 to 2014 (most of Europe and former British colonies) all demonstrate reduced trade deficits or greater trade surpluses, in the counterfactual relative to the baseline. Conversely, emerging economies that experience relatively sharp increases in the working age share from 1970-2014 (China, India, Indonesia, Mexico, South Korea, Turkey) demonstrate increased trade deficits or reduced trade surpluses, in the counterfactual relative to the baseline. The reason is that that with counterfactual preference shocks, the demographic-induced demand for saving by emerging economies is eliminated.

Labor shocks generally have the opposite impact on trade imbalances than saving shocks do. With counterfactual labor shocks, the United States accumulates a slightly larger trade deficit compared to the data, whereas China's trade surplus is magnified. Again, this result is fairly systematic with respect to advanced versus emerging economies. Advanced economies with relative declines in the working age share generally experience lower ratios of net exports to GDP, compared to the baseline, whereas emerging economies with relative increases in the working age share generally experience higher ratios. The reason is that a growing workforce raises the return to capital investment, thereby attracting financial resources from abroad resulting in more borrowing and lower net exports.

In sum, relatively fast increases in the working age share induce higher propensity to save, while at the same time generating higher propensity to supply labor thereby triggering capital inflows (borrowing). On net, the saving channel is quantitatively more prominent, so relatively fast increases in the working age share induce a greater demand for saving and a trade surplus, all else equal.

\subsection{Population growth as a driver of imbalances}

Aside from the age distribution, population size itself is an important demographic characteristic. In particular, countries exhibit noticeable differences in population growth rates. For instance, from 1970 to 2014 Germany's population grew by less than one-tenth of a percent per year, on average, whereas Mexico's population grew by over two percent. (Figure D.2 in Appendix $\mathrm{D}$ shows the observed and projected population growth rates for all countries.)

In a standard closed economy neoclassical growth model, changes in the population growth rate have a similar effect of the consumption-saving tradeoff as a change in the discount factor. That is, in anticipation of higher population in the future, households invest (save) more in order to smooth consumption per capita. This incentive is present in the open economy model, but the general equilibrium effects occur through the real exchange 
rate instead, since saving can be achieved via borrowing and lending instead of through investment. Moreover, in an open economy model, borrowing and lending is impacted by relative differences in population growth across countries.

Recall the expression for measured productivity: $\left(A_{i t}\right)^{\nu_{i t}}\left(\pi_{i i t}\right)^{-1 / \theta}$. All else equal, higher population implies higher home trade share and, hence, lower measured productivity. So if a country expects fast population growth, it also expects to have a deterioration in its measured productivity and in its RER.

To make this point more concrete, define country $i$ 's RER as the trade-weighted average of all of its bilateral RERs, $\frac{P_{i}}{P_{j}}$, for all $j \neq i$ :

$$
R E R_{i t}=\frac{\sum_{j=1, j \neq i}^{I}\left(\frac{P_{i t}}{P_{j t}}\right)\left(\operatorname{Tr} d_{i j t}+\operatorname{Tr} d_{j i t}\right)}{\sum_{j=1, j \neq i}^{I}\left(\operatorname{Tr} d_{i j t}+\operatorname{Tr} d_{j i t}\right)} .
$$

On the vertical axis of Figure 8 is the log-difference between RER appreication in the baseline model, and that in the counterfactual with population fixed over time. Countries near the bottom of the vertical axis realize a depreciation in their RER in the baseline compared to the counterfactual. On the horizontal axis is the log-change in observed population from 1970 to 2014. Countries on the far right of the horizontal axis have high observed population growth from 1970 to 2014. The negative relationship indicates that higher population growth induces a real devaluation. The intuition is that countries that have high population growth want to save more to smooth consumption per capita. In equilibrium, these countries will face relatively rising consumer prices and a declining real exchange rate, all else equal. Emerging economies experience faster population growth than advanced economies, on average, which partly contributes to a relatively higher saving rate, all else equal.

Since the model is deterministic, a realized change in any bilateral RER is equal to the change in real interest rate differential between the two countries. An obvious corollary is that a net increase in immigration would induce more saving. Taylor and Williamson (1994) take a historical perspective along these lines and argue that capital flows from Britain to the New World were effectively an intergenerational transfer from old savers to young savers. 
Figure 8: Difference in real exchange appreciation against observed population growth

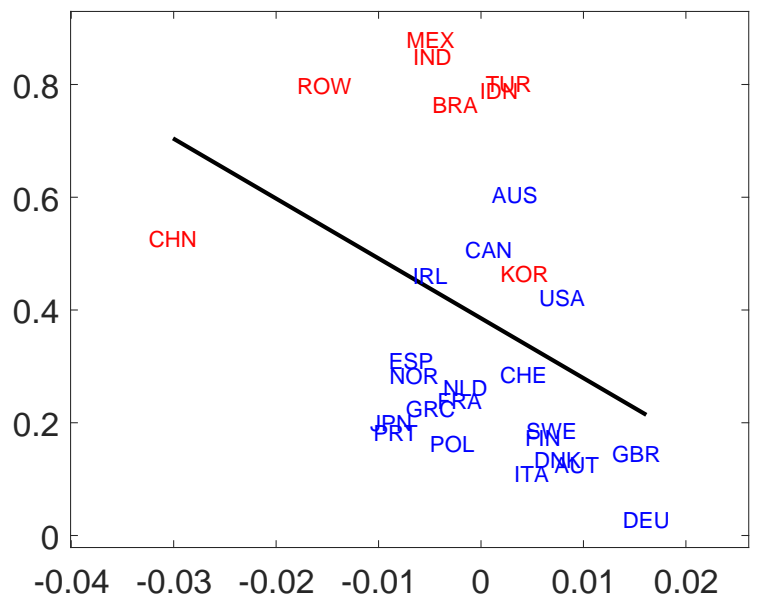

Notes: Vertical axis is $\ln \left(R E R_{i 2014}^{\text {base }} / R E R_{i 1970}^{\text {base }}\right)-\ln \left(R E R_{i 2014}^{c f} / R E R_{i 1970}^{c f}\right)$. RER denotes the real exchange rate given by equation (14). Superscript $c f$ refers to the counterfactual with population simultaneously fixed in every country at 1970 levels. Superscript base refers to the baseline model (data). Horizontal axis is $\ln \left(N_{i 2014} / N_{i 1970}\right)$. Emerging economies are in red and advanced economies, in blue.

\subsection{Demographics as a partial resolution to the allocation puzzle}

Figure 9 depicts the allocation puzzle. Specifically, there is clearly no negative correlation between the ratio of net exports to GDP and TFP growth. The slope of the best fit curve between (elasticity of) the ratio of net exports to GDP and TFP growth is $7.5 \%$.

This section considers how various forces contribute to the allocation puzzle by simulating counterfactuals in which particular exogenous forces are held constant over time. In each counterfactual, I recompute the elasticity between the ratio of net exports to GDP and TFP growth. Table 3 reports the elasticity for the baseline and counterfactual specifications.

Freezing the age distribution In this counterfactual I freeze the demographic forcessaving shocks and labor shocks - at their initial levels, as in equation 13 .

Removing changes in the age distribution unveils a strong negative relationship between net exports and TFP growth. The elasticity is significantly negative, at $-19.4 \%$, which is much lower than in the baseline.

This finding indicates an intimate relationship between changes in the age distribution and the rate of TFP growth. Countries that experienced fast TFP growth, but did not run trade deficits, also tend to be countries that experienced relatively fast increases in their 
Figure 9: Ratio of net exports to GDP against labor TFP growth

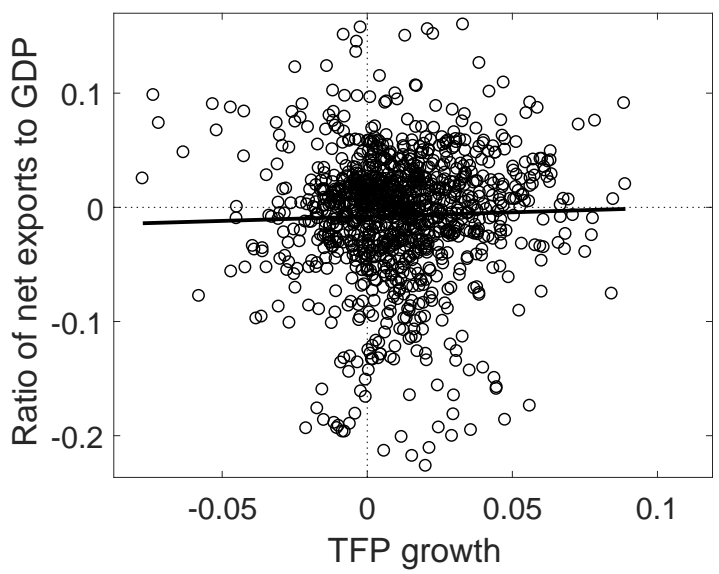

Notes: Horizontal axis is the average annual growth in labor productivity during five year windows. Vertical axis is the average ratio of net exports to GDP during five year windows. Windows run from $[1970,1974]-[2010,2014]$. The line corresponds to the best fit curve using OLS.

Table 3: Elasticity between ratio of net exports to GDP and TFP growth

\begin{tabular}{lcc}
\hline \hline Specification & Elasticity & (S.E.) \\
\hline Baseline model (data) & $7.5 \%$ & $(7.5 \%)$ \\
Counterfactual: Freezing the age distribution & $-19.4 \%$ & $(9.8 \%)$ \\
Counterfactual: Freezing saving distortions & $-96.3 \%$ & $(50.5 \%)$ \\
Counterfactual: Freezing labor distortions & $40.0 \%$ & $(12.4 \%)$ \\
Counterfactual: Freezing investment distortions & $-2.7 \%$ & $(13.7 \%)$ \\
Counterfactual: Freezing bilateral trade distortions & $102.7 \%$ & $(15.9 \%)$ \\
\hline
\end{tabular}

Notes: The elasticity is the slope of the line corresponding to the best fit curve using OLS (see Figure 9 for the case of the baseline model/data). The $y$-variable in the regression is the average annual growth in TFP during five year windows. The $\mathrm{x}$-variable in the regression is the average ratio of net exports to GDP during five year windows. Windows run from [1970,1974]-[2010,2014].

working age shares. That is, the allocation puzzle is partly due to the fact that fast growing emerging economies have an incentive to save because of demographics.

Freezing saving distortions In this counterfactual I freeze the saving distortion in each country at its initial level:

$$
\widetilde{\tau}_{i t+1}^{\mathcal{A}}=\tau_{i 1971}^{\mathcal{A}}
$$


with $\widetilde{\tau}_{i 1970}^{\mathcal{A}}=\tau_{i 1970}^{\mathcal{A}}=0$. The relationship between trade imbalances and TFP growth becomes strongly negative, with an elasticity of $-96 \%$. This finding suggests that the saving distortion encompasses important frictions that give rise to the allocation puzzle.

This is no surprise, given the findings in Gourinchas and Jeanne (2013). However, there is a subtle difference here: The saving distortion in my model is only one part of the overall saving wedge explored by Gourinchas and Jeanne (2013). The other component is the demographic-induced saving shock. Demographics chip away at saving wedge in this sense, but a sizeable chunk remains to be explained.

Alfaro, Kalemli-Ozcan, and Volosovych (2008) argue that much of the puzzle - and the saving wedge - is about public saving. While large portions of government saving are influenced by demographics through pensions, government saving is likely affected by nondemographic forces such as un-modeled political economy features. Such mechanisms are beyond the scope of this paper.

Freezing labor distortions In this countrfactual I freeze the labor distortion in each country at its initial level:

$$
\widetilde{\tau}_{i t}^{L}=\tau_{i 1970}^{L}
$$

The elasticity of the ratio of net exports to GDP with respect to TFP growth is $40 \%$. This elasticity is greater than that in the baseline, implying that labor distortions do not systematically explain the allocation puzzle, but actually make it more puzzling.

Ohanian, Restrepo-Echavarria, and Wright (2018) argue that the labor wedge explains why capital flew out of Latin America and into Asia from 1950-1970. In their model, the labor wedge is computed similarly to mine, but the distortionary component is not separated from the demographic component (preference shock). I do not rule out the possibility that the labor distortion is not important for certain regional flows over certain time periods, but I instead study the period 1970-2014 across a much larger set of countries.

Freezing investment distortions In this countrfactual I freeze the investment distortion in each country at its initial level:

$$
\frac{1-\widetilde{\tau}_{i t+1}^{K}}{1-\widetilde{\tau}_{i t}^{K}}=\frac{1-\tau_{i 1971}^{K}}{1-\tau_{i 1970}^{K}},
$$

with $\widetilde{\tau}_{i 1970}^{K}=\tau_{i 1970}^{K}=0$. The elasticity of the ratio of net exports to GDP with respect to TFP growth is $-2.7 \%$. This elasticity is slightly negative, indicating that investment distortions 
systematically explain some of the allocation puzzle. These distortions capture frictions pertaining to investment, such as those in Buera and Shin (2017), as well as institutional problems that discourage investment, such as those discussed in Aguiar and Amador (2011).

Freezing bilateral trade distortions I decompose the bilateral trade costs (the portion that melts away, $d-1)$ into a trend component and a bilateral distortionary component:

$$
\left(d_{i j t}-1\right)=\mathcal{D}_{t} \times \varepsilon_{i j t}^{d} .
$$

The estimated trend component is then

$$
\widehat{\mathcal{D}}_{t}=\exp \left(\frac{1}{I \times(I-1)} \sum_{i=1}^{I} \sum_{\substack{j=1 \\ j \neq i}}^{I} \ln \left(d_{i j t}-1\right)\right)
$$

which steadily declines from 7.7 in 1970 to 3.6 in 2014, capturing reductions in shipping costs as well as large-scale tariff reductions implemented under the General Agreement on Tariffs and Trade and subsequently the World Trade Organization. The distortionary component captures changes in bilateral trade costs, such as bilateral trade agreements, for instance, or other policies implemented unilaterally.

In this countrfactual I freeze the bilateral trade distortions between each country at their initial levels and construct counterfactual trade costs:

$$
\widetilde{d}_{i t}=1+\widehat{\mathcal{D}}_{t} \times \widehat{\varepsilon}_{i j 1970}^{d}
$$

The elasticity of the ratio of net exports to GDP with respect to TFP growth is 103\%, indicating that asymmetries in trade distortions don't reconcile the allocation puzzle.

This result does not mean that asymmetries is trade costs are not important for explaining specific bilateral trade imbalances. For instance, much has been made in the political arena of unequal trade costs, specifically between China and the United States, both in terms of levels and changes. Indeed, in this counterfactual the U.S. bilateral trade deficit with China disappears as of 2014, compared to being 1.8 percent of U.S. GDP in the data. This finding is consistent with Alessandria and Choi (2019), who argue that asymmetric changes in trade costs faced by the U.S. influenced the U.S. trade deficit. 


\section{Conclusion}

The paper builds a dynamic, multicountry, Ricardian model of trade, where dynamics are driven by international borrowing and lending and capital accumulation. Trade imbalances arise endogenously as the result of relative shifts in technologies, trade costs, factor market distortions, and demographics. All of the exogenous forces are calibrated using a wedge accounting procedure so that the model rationalizes past and projected national accounts data and bilateral trade flows across 28 countries from 1970-2060.

Cross-country differences in changes in the age distribution systematically drive both the direction and magnitude of trade imbalances. On average, a one percentage point increase in a country's working age share, relative to that of the entire world, implies a one-third percentage point increase in its net exports to GDP. Demographic trends since 1970 contributed positively to net exports in emerging economies with quickly rising working age shares, and contributed negatively to net exports in advanced economies with slowly rising, or even falling, working age shares. The systematic relationship between economic growth rates and changes in the age distribution provides a channel in which resources flow from fast-growing emerging economies to slower-growing advanced economies, thereby alleviating the allocation puzzle.

The results in this paper allude to a relationship between TFP growth and changes in demographics. Countries that experienced fast TFP growth, but did not run trade deficits, tend to be the same countries that experienced relatively fast increases in their working age shares. Such a relationship can emerge from two distinct channels. One is that less developed countries tend to have higher fertility rates and, hence, younger populations. Another is that individuals become more productive over their lifetime, so older populations tend to have higher productivity. Digging into this relationship is beyond of the scope of this paper. Future work could aim at developing methods to solve models in which life-cycle features are embedded into multi-country, dynamic settings, where demographics affect the evolution of productivity in addition to saving propensities and labor supply. 


\section{References}

Aguiar, Mark and Manuel Amador. 2011. "Growth in the Shadow of Expropriation." Quarterly Journal of Economics 126 (2):651-697. URL https://doi.org/10.1093/qje/ qjr015.

Alessandria, George and Horag Choi. 2019. "The Dynamics of the Trade Balance and the Real Exchange Rate: The J Curve and Trade Costs?" Working Paper 25563, National Bureau of Economic Research. URL https://doi.org/10.3386/w25563.

Alessandria, George, Horag Choi, and Kim Ruhl. 2018. "Trade Adjustment Dynamics and the Welfare Gains from Trade." Working paper.

Alfaro, Laura, Sebnem Kalemli-Ozcan, and Vadym Volosovych. 2008. "Why Doesn't Capital Flow From Rich to Poor Countries? An Empirical Investigation." Review of Economics and Statistics 90 (2):347-368. URL https://doi.org/10.1162/rest.90.2.347.

Alvarez, Fernando. 2017. "Capital Accumulation and International Trade." Journal of Monetary Economics 91 (C):1-18. URL https://doi.org/10.1016/j.jmoneco.2017. 09.005.

Alvarez, Fernando and Robert E. Lucas. 2007. "General Equilibrium Analysis of the EatonKortum Model of International Trade." Journal of Monetary Economics 54 (6):1726-1768. URL https://doi.org/10.1016/j.jmoneco.2006.07.006.

Backus, David, Thomas Cooley, and Espen Henriksen. 2014. "Demography and LowFrequency Capital Flows." Journal of International Economics 92:S94-S102. URL https://doi.org/10.1016/j.jinteco.2014.01.006.

Bernanke, Ben S. 2005. "The Global Saving Glut and the U.S. Current Account Deficit." Tech. rep.

Blanchard, Olivier J. 1985. "Debt, Deficits, and Finite Horizons." Journal of Political Economy 93 (2):223-247. URL https://doi.org/10.1086/261297.

Börsch-Supan, Axel, Alexander Ludwig, and Joachim Winter. 2006. "Aging, Pension Reform, and Capital Flows: A Multi-Country Simulation Model." Economica 73:625-658. URL https://doi.org/10.1111/j.1468-0335.2006.00526.x. 
Brooks, Robin. 2003. "Population Aging and Global Capital Flows in a Parallel Universe." IMF Economic Review 50 (2):200-221. URL https://doi.org/10.5089/ 9781451857023.001 .

Buera, Francisco J. and Yongseok Shin. 2017. "Productivity Growth and Capital Flows: The Dynamics of Reforms." American Economic Journal: Macroeconomics 9 (3):147-85. URL https : //doi .org/10.1257/mac . 20160307.

Caliendo, Lorenzo, Maximiliano Dvorkin, and Fernando Parro. 2015. "Trade and Labor Market Dynamics.” Working Paper 21149, National Bureau of Economic Research. URL https://doi.org/10.3386/w21149.

Carroll, Christopher D., Jody Overland, and David N. Weil. 2000. "Saving and Growth with Habit Formation." American Economic Review 90 (3):341-355. URL https://doi .org/ 10.1257/aer.90.3.341.

Caselli, Francesco and James Feyrer. 2007. "The Marginal Product of Capital." Quarterly Journal of Economics 122 (2):535-568. URL https://doi.org/10.1162/qjec.122.2. 535 .

Chari, V.V., Patrick J. Kehoe, and Ellen R. McGrattan. 2007. "Business Cycle Accounting." Econometrica 75 (3):781-836. URL https://doi.org/10.1111/j.1468-0262. $2007.00768 . x$.

Eaton, Jonathan, Samuel Kortum, and Brent Neiman. 2016. "Obstfeld and Rogoff's International Macro Puzzles: A Quantitative Assessment." Journal of Economic Dynamics and Control 72:5-23. URL https://doi.org/10.1016/j.jedc.2016.06.002.

Eaton, Jonathan, Samuel Kortum, Brent Neiman, and John Romalis. 2016. "Trade and the Global Recession." American Economic Review 106 (11):3401-3438. URL https: //doi.org/10.1257/aer.20101557.

Feenstra, Robert C., Robert Inklaar, and Marcel P. Timmer. 2015. "The Next Generation of the Penn World Table." American Economic Review 105 (10):3150-3182. URL https: //doi.org/10.1257/aer.20130954.

Ferrero, Andrea. 2010. "A Structural Decomposition of the U.S. Trade Balance: Productivity, Demographics and Fiscal Policy." Journal of Monetary Economics 57 (4):478-490. URL https://doi.org/10.1016/j.jmoneco.2010.04.004. 
Gollin, Douglas. 2002. "Getting Income Shares Right." Journal of Political Economy 110 (2):458-474. URL https://doi.org/10.1086/338747.

Gourinchas, Pierre-Olivier and Olivier Jeanne. 2013. "Capital Flows to Developing Countries: The Allocation Puzzle." The Review of Economic Studies 80 (4):1422-1458. URL https://doi.org/10.1093/restud/rdt004.

Higgins, Matthew. 1998. "Demography, National Savings, and International Capital Flows." International Economic Review 39 (2):343-369. URL https://doi.org/10. $2307 / 2527297$.

İmorohoğlu, Ayşe and Kai Zhao. 2018a. "The Chinese Saving Rate: Long-Term Care Risks, Family Insurance, and Demographics." Journal of Monetary Economics 96:33-52. URL https://doi.org/10.1016/j.jmoneco.2018.03.001

. 2018b. "Household Saving, Financial Constraints, and the Current Account in China." Working paper. URL https://ideas.repec.org/p/uct/uconnp/2018-15. html.

Kehoe, Timothy J., Kim J. Ruhl, and Joseph P. Steinberg. 2018. "Global Imbalances and Structural Change in the United States." Journal of Political Economy 126 (1):761-796. URL https://doi.org/10.1086/696279.

Krueger, Dirk and Alexander Ludwig. 2007. "On the Consequences of Demographic Change for Rates of Returns to Capital, and the Distribution of Wealth and Welfare." Journal of Monetary Economics 54 (1):49-87. URL https://doi.org/10.1016/j.jmoneco.2006. 12.016.

Lucas, Robert E. 1990. "Why Doesn't Capital Flow from Rich to Poor Countries?" American Economic Review 80 (2):92-96.

Maliar, Lilia, Serguei Maliar, John Taylor, and Inna Tsener. 2015. "A Tractable Framework for Analyzing a Class of Nonstationary Markov Models." Working Paper 21155, National Bureau of Economic Research. URL https://doi.org/10.3386/w21155.

Obstfeld, Maurice and Kenneth Rogoff. 2001. The Six Major Puzzles in International Macroeconomics: Is there a Common Cause? Cambridge, MA: MIT Press, 339-390. 
Ohanian, Lee E., Paulina Restrepo-Echavarria, and Mark L. J. Wright. 2018. "Bad Investments and Missed Opportunities? Postwar Capital Flows to Asia and Latin America." American Economic Review 108 (12):3541-3582. URL https://doi.org/10.1257/aer. 20151510.

Organization for Economic Cooperation and Development. 2014. "Long-Term Baseline Projections, No. 95 (Edition 2014)." Tech. rep. URL/content/data/data-00690-en.

Peterman, William B. 2016. "Reconciling Micro And Macro Estimates Of The Frisch Labor Supply Elasticity." Economic Inquiry 54 (1):100-120. URL https://doi.org/10.1111/ ecin.12252.

Prasad, Eswar S., Raghuram G. Rajan, and Arvind Subramanian. 2007. "Foreign Capital and Economic Growth." Brookings Papers on Economic Activity 1:153-230.

Ravikumar, B., Ana Maria Santacreu, and Michael Sposi. 2018. "Capital Accumulation and Dynamic Gains from Trade." Working Paper 296, Federal Reserve Bank of Dallas, Globalization Institute. URL https://doi .org/10.24149/gwp296r2.

Reyes-Heroles, Ricardo. 2016. "The Role of Trade Costs in the Surge of Trade Imbalances." Working paper.

Simonovska, Ina and Michael E. Waugh. 2014. "The Elasticity of Trade: Estimates and Evidence." Journal of International Economics 92 (1):34-50. URL https://doi.org/ $10.1016 / \mathrm{j} \cdot \mathrm{j}$ inteco.2013.10.001.

Song, Zheng, Kjetil Storesletten, and Fabrizio Zilibotti. 2011. "Growing Like China." American Economic Review 101 (1):196-233. URL https://doi.org/10.1257/aer.101.1.196.

Sposi, Michael. 2012. "Evolving Comparative Advantage, Structural Change, and the Composition of Trade." Working paper. URL https://sites.google.com/site/ michaelsposi/files/jmp_sposi_2012-02-27.pdf.

Steinberg, Joseph. 2019. "On the Source of U.S. Trade Deficits: Global Saving Glut or Domestic Saving Draught?" Journal of International Economics 31:200-223. URL https: //doi.org/10.1016/j.red.2018.07.002.

Taylor, Alan M. and Jeffrey G. Williamson. 1994. "Capital Flows to the New World as an Intergenerational Transfer." Journal of Political Economy 102 (2):348-371. URL https://doi.org/10.1086/261935. 
Timmer, Marcel P., Erik Dietzenbacher, Bart Los, Robert Stehrer, and Gaaitzen J. de Vries. 2015. "An Illustrated User Guide to the World Input-Output Database: the Case of Global Automobile Production." Review of International Economics 23 (3):575-605. URL https://doi .org/10.1111/roie.12178.

United Nations. 2015. "World Population Prospects: The 2015 Revision, Key Findings and Advance Tables." Working Paper ESA/P/WP.241, United Nations, Department of Economic and Social Affairs, Population Division.

Wei, Shang-Jin and Xiaobo Zhang. 2011. "The Competitive Saving Motive: Evidence from Rising Sex Ratios and Savings Rates in China." Journal of Political Economy 119 (3):511564. URL https://doi .org/10.1086/660887.

Yaari, Menahem E. 1965. "Uncertain Lifetime, Life Insurance, and the Theory of the Consumer." The Review of Econmic Studies 32 (2):137-150.

Yang, Dennis Tao, Junsen Zhang, and Shaojie Zhou. 2012. Why Are Saving Rates So High in China? University of Chicago Press, 249-278. URL https://doi.org/10.7208/ chicago/9780226237268.003.0006.

Zylkin, Thomas. 2016. "Feeding China's Rise: The Growth Effects of Trading with China, 1993-2011." Working paper. URL http://www.tomzylkin.com/uploads/4/1/ 0/4/41048809/china_growth_effects.pdf. 


\section{A Data}

This section of the Appendix describes the sources of data as well as adjustments made to the data. Sources include the 2016 release of the World Input-Output Database (Timmer, Dietzenbacher, Los, Stehrer, and de Vries, 2015, (WIOD)), version 9.0 of the Penn World Table (Feenstra, Inklaar, and Timmer, 2015, (PWT)), Organization for Economic Cooperation and Development (2014) Long-Term Projections Database (OECD), 2015 revision of the United Nations (2015) World Population Prospects (UN), the International Monetary Fund Direction of Trade Statistics (IMFDOTS), and Federal Reserve Economic Data (FRED). Table A.1 summarizes the data raw data.

Table A.1: Model variables and corresponding data sources

\begin{tabular}{llll}
\hline \hline Variable & Model & Data source & Data source \\
description & counterpart & $1970-2014$ & $2015-2060$ \\
\hline Age distribution & $\mathrm{s}_{i t}$ & $\mathrm{UN}$ & $\mathrm{UN}$ \\
Population & $N_{i t}$ & PWT & UN \\
Employment & $L_{i t}$ & PWT & OECD \\
Value added* & $w_{i t} L_{i t}+r_{i t} K_{i t}$ & PWT \& WIOD & OECD \\
Price of consumption** & $P_{i t}^{c}$ & PWT & Imputed \\
Price of investment** & $P_{i t}^{x}$ & PWT & Imputed \\
Price of composite intermediate** & $P_{i t}$ & PWT & Imputed \\
Risk free nominal interest rate & $q_{t}$ & FRED & Imputed \\
Consumption*** & $C_{i t}$ & PWT & Imputed \\
Investment** & $X_{i t}$ & PWT & OECD \\
Initial capital stock** & $K_{i 1}$ & PWT & N/A \\
Gross output* & $P_{i t} Y_{i t}$ & Imputed \& WIOD & Imputed \\
Bilateral trade flow* & $P_{i t} Q_{i t} \pi_{i j t}$ & IMFDOTS \& WIOD & Imputed \\
Absorption* & $P_{i t} Q_{i t}$ & Imputed \& WIOD & Imputed \\
\hline
\end{tabular}

Notes: The age distribution tracks the working age share and the retired share of the population: $\mathrm{s}_{i t}=\left(s_{i t}^{15-64}, s_{i t}^{65+}\right) .{ }^{*}$ Values are measured in current prices using market exchange rates. ${ }^{* *}$ Prices are measured using PPP exchange rates. ${ }^{* * *}$ Quantities are measured as values deflated by prices.

Selection of countries is based on constructing a panel with data spanning 1970-2060. The countries (3-digit isocodes) are: Australia (AUS), Austria (AUT), Brazil (BRA), Canada $(\mathrm{CAN})$, China (CHN), Denmark (DNK), Finland (FIN), France (FRA), Germany (DEU), Greece (GRC), India (IND), Indonesia (IDN), Ireland (IRL), Italy (ITA), Japan (JPN), South Korea (KOR), Mexico (MEX), Netherlands (NLD), Norway (NOR), Poland (POL), 
Portugal (PRT), Spain (ESP), Sweden (SWE), Switzerland (CHE), Turkey (TUR), United Kingdom (GBR), United States (USA), and Rest-of-world (ROW). Below I provide descriptions of how the data from 1970-2014 are constructed, and separately for 2015-2060.

\section{Constructing realized data from 1970-2014}

- Age distribution data from 1970-2014 come from the UN. For the ROW aggregate I take the age distribution data for the "world" aggregate that the UN reports, and subtract the sum of the data for the countries in my sample.

- Population data from 1970-2014 come directly from PWT. For the ROW aggregate, the population is computed as the sum of the entire population across all countries in PWT, minus the sum of the population across countries in my sample.

- Employment data from 1970-2014 come directly from PWT. For the ROW aggregate, employment is computed as the sum of across all countries in PWT, minus the sum across countries in my sample.

- Value added in current U.S. dollars is taken from various sources. From 2000-2014, these data are obtained from WIOD and are computed as the sum of all value added across every industry in each country-year. From 1970-2000 these data are obtained from PWT and computed as output-side real GDP at current PPP times the price level of GDP at current PPP exchange rate (relative to the U.S.). The data from PWT are multiplicatively spliced to WIOD as of the year 2000.

- Price of consumption from 1970-2014 is computed directly from PWT. For ROW, it is computed as the ratio of consumption in current prices relative to consumption in PPP prices. Consumption in ROW is computed as the sum across all countries in PWT minus the sum across countries in my sample.

- Price of investment is computed analogously to the price of consumption.

- Price of the composite intermediate good from 1970-2014 is constructed using various data in PWT. I take a weighted average of the price level of imports and of exports, each of which come directly from PWT. The weight applied to imports is the country's import share in total absorption, and the weight applied to exports is the country's home trade share in total absorption. Trade and absorption data are described below. For ROW, I compute the price of imports as the ratio of ROW imports in current 
prices divided by ROW imports in PPP prices. ROW imports is computed as the sum of imports across all countries in PWT minus the sum across countries in my sample.

- The risk free nominal rate of interest is defined as the annual yield on the 10-year U.S. Treasury note, taken from Federal Reserve Economic Data (FRED).

- Consumption quantities are calculated in two steps. The first step computes total consumption expenditures as total value added minus investment expenditures, minus net exports. The second step deflates the consumption expenditure by the price of consumption. This way, consumption includes that of both households and government, and necessarily ensures that the national income identity holds in both the data and in the model.

- Investment quantities from 1970-2014 are computed from various data in the PWT. I begin by computing the nominal investment rate (ratio of expenditures on investment as a share of GDP in current prices). I then multiply the nominal investment rate by GDP in current U.S. dollars to arrive at total investment spending in current U.S. dollars. Finally, I deflate the current investment expenditures by the price of investment.

- Initial capital stock is taken directly from PWT. Capital stock in ROW is computed as the sum across all countries in PWT minus the sum across countries in my sample.

- Gross output in current U.S. dollars from 2000-2014 is obtained from WIOD and is computed as the sum of all gross output across every industry in each country-year. Prior to 2000, I impute these data using the ratio of value added to gross output in 2000, and applying that ratio to scale value added in each year prior to 2000.

- Bilateral trade in current U.S dollars from 2000-2014 is computed directly from WIOD as the sum of all trade flows (intermediate usage and final usage) across all industries. Prior to 2000, bilateral trade flows are obtained from the IMFDOTS. Bilateral trade flows with ROW are computed as imports (exports) to (from) the world minus the sum of imports (exports) to (from) the countries in my sample. These data are multiplicatively spliced to the WIOD data as of the year 2000.

- Absorption in current U.S. dollars from 2000-2014 is computed using WIOD data as gross output minus net exports, summed across all industries. 


\section{Constructing projected data from 2015-2060}

- Age distribution data from 2015-2060 come from the UN. For the ROW aggregate I take the age distribution data for the "world" aggregate that the UN reports, and subtract the sum of the data for the countries in my sample.

- Population data from 2015-2060 are taken directly from UN and spliced to the PWT levels as of the year 2014 .

- Employment data from 2015-2060 are taken directly from OECD and spliced to the PWT levels as of the year 2014.

- From 2015-2060, data on value added in current U.S. dollars are obtained from OECD projections and computed as real GDP per capita (in constant, local currency units) times the population, times the price level (in local currency units), times the PPP level (relative to the U.S.), times the nominal exchange rate (local currency per U.S. dollar at current market prices). The data from OECD are multiplicatively spliced to WIOD as of the year 2014.

- Price of consumption from 2015-2060 is imputed by assuming equal growth rates to the price deflator for aggregate GDP, where the price deflator for aggregate GDP is directly computed using data in the OECD projections.

- Price of investment from 2015-2060 is imputed using information on its co-movement with the price of consumption. In particular, I estimate the relationship between growth in the relative price against a constant and a one-year lag in the relative price growth, for the years 1972-2014.

$$
\ln \left(\frac{P_{i t}^{c} / P_{i t}^{x}}{P_{i t-1}^{c} / P_{i t-1}^{x}}\right)=\beta_{0}+\beta_{1} \ln \left(\frac{P_{i t-1}^{c} / P_{i t-1}^{x}}{P_{i t-2}^{c} / P_{i t-2}^{x}}\right)+\varepsilon_{i t} .
$$

I use the estimates from equation (A.1) to impute the sequence of prices for investment from 2015-2060, given the already imputed data for the price of consumption during these years.

- Price of the composite intermediate good from 2015-2060 is imputed by first constructing data for the price of imports and exports. Prices of imports and exports are each computed analogously to the price of investment by estimating equation (A.1) for each 
series. I then take a weighted average of the price levels of imports and of exports to determine the price of the composite good. The weight applied to imports is the country's import share in total absorption, and the weight applied to exports is the country's home trade share in total absorption. Trade and absorption data are described below.

- The risk free nominal rate of interest is recovered using an intertemporal Euler equation together with projections for consumption, population, and the price level of consumption for the United States only. Specifically, I normalize the preference wedge in the United States to $\omega_{U t}^{\mathcal{A}}=1$, for all years $t \geq 2015$ and recover the world interest rate as

$$
\frac{C_{U t+1} / N_{U t+1}}{C_{U t} / N_{U t}}=\beta \omega_{U t}^{\mathcal{A}}\left(\frac{1+q_{t+1}}{P_{U t+1}^{c} / P_{U t}^{c}}\right)
$$

for all years $t \geq 2014$. This implies an average world interest rate of 3.4 percent from 2015-2060.

Figure A.1: World interest rate

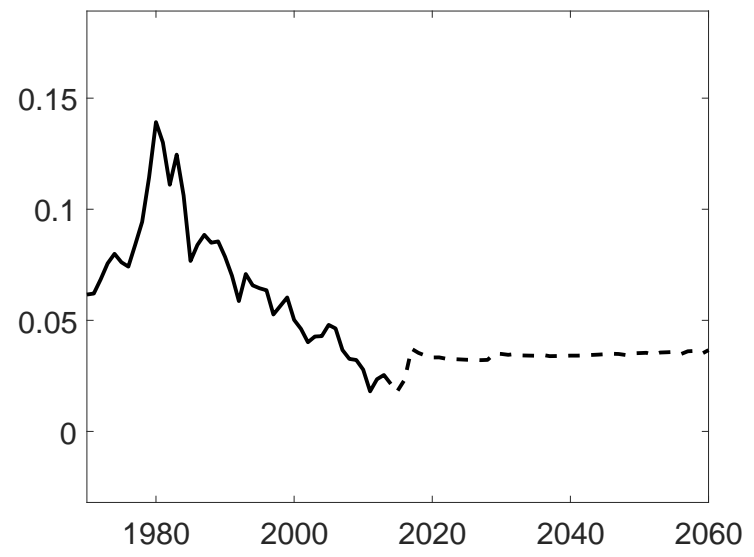

Notes: Solid lines - observed annual yield on 10-year U.S. Treasury. Dashed lines - Imputed using equation (A.2).

- Consumption quantities from 2015-2060 are calculated in the same exact way as done for 1970-2014.

- Investment quantities from 2015-2060 are computed from various variables in the OECD projections. I begin by imputing the nominal investment rate (ratio of expenditures on investment to GDP in current prices) using information on its co-movement with the relative prices. I estimate the relationship between the investment rate against 
a country-fixed effect, the lagged investment rate, the contemporaneous and lagged relative price of investment, and the contemporaneous and lagged real GDP per capita for the years 1971-2014. Letting $\rho_{i t}=\frac{P_{x i t} X_{i t}}{G D P_{i t}}$ denote the investment rate,

$$
\begin{aligned}
\ln \left(\frac{\rho_{i t}}{1-\rho_{i t}}\right) & =\alpha_{i}+\beta_{1} \ln \left(\frac{\rho_{i t-1}}{1-\rho_{i t-1}}\right) \\
& +\beta_{2} \ln \left(\frac{P_{i t}^{x}}{P_{i t}^{c}}\right)+\beta_{3} \ln \left(\frac{P_{i t-1}^{x}}{P_{i t-1}^{c}}\right)+\beta_{4} \ln \left(y_{i t}\right)+\beta_{5} \ln \left(y_{i t-1}\right)+\varepsilon_{i t} .
\end{aligned}
$$

Using $\ln (\rho /(1-\rho))$ to ensures that the imputed values of $\rho$ are bounded between 0 and 1. I use the estimated coefficients from equation A.3 together with projections on the relative price and income per capita to construct projections for the investment rate. I then multiply the nominal investment rate by GDP in current U.S. dollars (available in the OECD projections) to arrive at total investment spending in current U.S. dollars. Finally, I deflate the investment expenditures by the price of investment.

- Gross output in current U.S. dollars from 2015-2060 is imputed using the ratio of value added to gross output in 2014, and applying that ratio to scale value added in each year after 2014. The value added data (GDP in current U.S. dollars) after 2014 is obtained directly from OECD projections.

- Bilateral trade in current U.S dollars from 2015-2060 are constructed in multiple steps. First, let $x_{i j t}=\frac{X_{i j t}}{G O_{j t}-E X P_{j t}}$ be the ratio of country $j$ 's exports to country $i$, relative to country $j$ 's gross output net of its total exports. I then estimate how changes in this trade share co-moves with changes in the importer's aggregate import price index, changes in the exporter's aggregate export price index, and changes in both the importer's and exporter's levels of GDP:

$$
\begin{aligned}
\ln \left(\frac{x_{i j t}}{x_{i j t-1}}\right) & =\beta_{1} \ln \left(\frac{P_{i t}^{m}}{P_{i t-1}^{m}}\right)+\beta_{2} \ln \left(\frac{P_{j t}^{x}}{P_{j t-1}^{x}}\right) \\
& +\beta_{3} \ln \left(\frac{G D P_{i t}}{G D P_{i t-1}}\right)+\beta_{4} \ln \left(\frac{G D P_{j t}}{G D P_{j t-1}}\right)+\varepsilon_{i t} .
\end{aligned}
$$

I use the estimated coefficients from equation $\mathrm{A} .4$ together with projections of prices of imports and of exports and levels of GDP to construct trade shares from 2015-2060. 
In the second step, I use the fact that country $i$ 's domestic sales is determined by

$$
X_{i i t}=\frac{G O_{i t}}{1+\sum_{j \neq i} x_{j i t}}
$$

where gross output and trade shares from 2015-2060 have already been constructed.

Finally, given projected domestic sales and trade shares, the bilateral trade flow is

$$
X_{i j t}=X_{j j t} x_{i j t}
$$

- Absorption in current U.S. dollars from 2015-2060 is gross output minus net exports.

\section{B Equilibrium conditions}

This section describes the solution to a perfect foresight equilibrium and allows for a more general CES utility function, $\frac{(C / N)^{1-1 / \sigma}}{1-1 / \sigma}$, with intertemporal elasticity of substitution, $\sigma \neq 1$.

Household optimization The representative household's optimal path for consumption satisfies two Euler equations:

$$
\begin{aligned}
& \frac{C_{i t+1} / N_{i t+1}}{C_{i t} / N_{i t}}=\beta^{\sigma}\left(\frac{\psi_{i t+1}}{\psi_{i t}}\right)^{\sigma}\left(1-\tau_{i t}^{\mathcal{A}}\right)^{\sigma}\left(\frac{1+q_{t+1}}{P_{i t+1}^{c} / P_{i t}^{c}}\right)^{\sigma} \\
& \frac{C_{i t+1} / N_{i t+1}}{C_{i t} / N_{i t}}=\beta^{\sigma}\left(\frac{\psi_{i t+1}}{\psi_{i t}}\right)^{\sigma}\left(\frac{\frac{r_{i t+1}}{P_{i t+1}^{c}}-\left(\frac{P_{i t+1}^{c}}{P_{i t+1}^{c}}\right) \Phi_{2}\left(K_{i t+2}, K_{i t+1}\right)}{\left(\frac{P_{i t}^{x}}{P_{i t}^{c}}\right) \Phi_{1}\left(K_{i t+1}, K_{i t}\right)}\right)^{\sigma}\left(\frac{1-\tau_{i t+1}^{K}}{1-\tau_{i t}^{K}}\right)^{\sigma} .
\end{aligned}
$$

The first Euler equation describes the trade-off between consumption and saving in oneperiod bonds, while the second Euler equation describes the trade-off between consumption and investment in physical capital. Investment is written as $X_{i t} \equiv \Phi\left(K_{i t+1}, K_{i t}\right)$, where $\Phi_{1}$ and $\Phi_{2}$ are the derivatives with respect to the first and second arguments, respectively.

Labor supply in each period is chosen to satisfy

$$
1-\frac{L_{i t}}{N_{i t}}=\left(\zeta_{i t}\right)^{\phi}\left(1-\tau_{i t}^{L}\right)^{-\phi}\left(\frac{w_{i t}}{P_{i t}^{c}}\right)^{-\phi}\left(\frac{C_{i t}}{N_{i t}}\right)^{\frac{\phi}{\sigma}} .
$$

Given $K_{i 1}$ and $\mathcal{A}_{i 1}$, the paths of consumption, net-purchases of bonds, investment in physical capital, and labor supply must satisfy the budget constraint and the accumulation 
technologies for capital and net-foreign assets:

$$
P_{i t}^{c} C_{i t}+\mathcal{A}_{i t+1}=\left(r_{i t} K_{i t}-P_{i t}^{x} X_{i t}\right)\left(1-\tau_{i t}^{K}\right)+w_{i t} L_{i t}\left(1-\tau_{i t}^{L}\right)+\left(1+q_{t}\right) \mathcal{A}_{i t}\left(1-\tau_{i t}^{\mathcal{A}}\right)+T_{i t} .
$$

Firm optimization Markets are perfectly competitive so firms set prices equal to marginal costs. Omitting time subscripts for now, denote the price of variety $v$, produced in country $j$ and purchased by country $i$, as $p_{i j}(v)$. Then $p_{i j}(v)=p_{j j}(v) d_{i j}$, where $p_{j j}(v)$ is the marginal cost of producing variety $v$ in country $j$. Since country $i$ purchases each variety from the country that can deliver it at the lowest price, the price in country $i$ is $p_{i}(v)=\min _{j=1, \ldots, I}\left[p_{j j}(v) d_{i j}\right]$. The price of the composite intermediate good in country $i$ at time $t$ is then

$$
P_{i t}=\gamma\left[\sum_{j=1}^{I}\left(\left(A_{j t}\right)^{-\nu_{j t}} u_{j t} d_{i j t}\right)^{-\theta}\right]^{-\frac{1}{\theta}},
$$

where $u_{j t}=\left(\frac{r_{j t}}{\alpha \nu_{j t}}\right)^{\alpha \nu_{j t}}\left(\frac{w_{j t}}{(1-\alpha) \nu_{j t}}\right)^{(1-\alpha) \nu_{j t}}\left(\frac{P_{j t}}{1-\nu_{j t}}\right)^{1-\nu_{j t}}$ is the unit cost for a bundle of inputs for intermediate-goods producers in country $j$ at time $t$.

One unit of the composite good can be converted into $\chi_{i t}^{c}$ consumption or into $\chi^{x}$ investment. Hence, price of consumption and investment are given by

$$
P_{i t}^{c}=\frac{P_{i t}}{\chi_{i t}^{c}}, \quad P_{i t}^{x}=\frac{P_{i t}}{\chi_{i t}^{x}}
$$

Next I define total factor usage $(K, L, M)$ and output $(Y)$ by summing over varieties.

$$
\begin{aligned}
K_{i t} & =\int_{0}^{1} K_{i t}(v) d v, & L_{i t} & =\int_{0}^{1} L_{i t}(v) d v, \\
M_{i t} & =\int_{0}^{1} M_{i t}(v) d v, & Y_{i t} & =\int_{0}^{1} Y_{i t}(v) d v .
\end{aligned}
$$

The term $L_{i t}(v)$ denotes the quantity of labor employed in the production of variety $v$ at time $t$. If country $i$ imports variety $v$ at time $t$, then $L_{i t}(v)=0$. Hence, $L_{i t}$ is the total quantity of labor employed in country $i$ at time $t$. Similarly, $K_{i t}$ is the total quantity of capital used, $M_{i t}$ is the total quantity of the composite good used as an intermediate input in production, and $Y_{i t}$ is the total quantity of output produced.

Cost minimization by firms implies that factor expenses exhaust the value of production:

$$
r_{i t} K_{i t}=\alpha \nu_{i t} P_{i t} Y_{i t}, \quad w_{i t} L_{i t}=(1-\alpha) \nu_{i t} P_{i t} Y_{i t}, \quad P_{i t} M_{i t}=\left(1-\nu_{i t}\right) P_{i t} Y_{i t} .
$$


That is, $\alpha \nu_{i t}$ is the fraction of the gross production that compensates capital services, $(1-$ $\alpha) \nu_{i t}$ compensates labor services, and $1-\nu_{i t}$ covers the cost of intermediate inputs.

Trade flows The fraction of country $i$ 's expenditures allocated to varieties produced by country $j$ is given by

$$
\pi_{i j t}=\frac{\left(\left(A_{j t}\right)^{-\nu_{j t}} u_{j t} d_{i j t}\right)^{-\theta}}{\sum_{\ell=1}^{I}\left(\left(A_{\ell t}\right)^{-\nu_{\ell t}} u_{\ell t} d_{i \ell t}\right)^{-\theta}} .
$$

Market clearing conditions Tax revenue is returned in lump sum to the household:

$$
\tau_{i t}^{K}\left(r_{i t} K_{i t}-P_{i t}^{x} X_{i t}\right)+\tau_{i t}^{L} w_{i t} L_{i t}+\tau_{i t}^{\mathcal{A}}\left(1+q_{i t}\right) \mathcal{A}_{i t}=T_{i t} .
$$

The supply of the composite good - an aggregate of all imported and domestic varietiesmust equal the demand., which consists of consumption, investment, and intermediate input.

$$
P_{i t}^{c} C_{i t}+P_{i t}^{x} X_{i t}+P_{i t} M_{i t}=P_{i t} Q_{i t}
$$

The balance of payments must hold in each country: the current account equals net exports plus net-foreign income. With net exports equal to gross output less gross absorption, this condition implies

$$
\mathcal{B}_{i t}=P_{i t} Y_{i t}-P_{i t} Q_{i t}+q_{t} \mathcal{A}_{i t}
$$

To close the model, the current account equals the change in the NFA position:

$$
\mathcal{A}_{i t+1}=\mathcal{A}_{i t}+\mathcal{B}_{i t}
$$

Remark The world interest rate is strictly nominal. As such, the value plays essentially no role other than pinning down a numéraire. Since my choice of numéraire is world GDP in each period, the world interest rate reflects the relative valuation of world GDP at two points in time. This interpretation is useful in guiding the solution procedure and also makes for straightforward mapping between model and data. That is, in the model the prices map into current units, as opposed to constant units. In other words, the model can be rewritten so that all prices are quoted in time-1 units (like an Arrow-Debreu world) with the world interest rate of zero and the equilibrium would yield identical quantities. 


\section{Solution algorithm}

In this section of the Appendix I describe the algorithm for computing the equilibrium transition path. Before going further into the algorithm, I introduce some notation. I denote the cross-country vector of a given variable at a point in time using vector notation, i.e., $\vec{K}_{t}=\left\{K_{i t}\right\}_{i=1}^{I}$ is the vector of capital stocks across countries at time $t$.

\section{C.1 Computing the equilibrium transition path}

Given the initial conditions- $\left(\vec{K}_{1}, \overrightarrow{\mathcal{A}_{1}}\right)$ - the equilibrium transition path consists of 17 objects: $\left\{\vec{w}_{t}, \vec{r}_{t}, q_{t}, \vec{P}_{t}, \vec{P}_{t}^{c}, \vec{P}_{t}^{x}, \vec{Y}_{t}, \vec{Q}_{t}, \vec{C}_{t}, \vec{X}_{t}, \vec{K}_{t+1}, \vec{L}_{t}, \vec{M}_{t}, \overrightarrow{\mathcal{B}}_{t}, \overrightarrow{\mathcal{A}}_{t+1}, \vec{T}_{t}, \overrightarrow{\vec{\pi}}_{t}\right\}_{t=1}^{T}$ (the double-arrow notation on $\overrightarrow{\vec{\pi}}_{t}$ indicates that this is an $I \times I$ matrix in each period $t$ ). Table C.1 provides a list of 17 equilibrium conditions that these objects must satisfy.

The solution procedure is boils down to two loops, similar to the algorithm in Ravikumar, Santacreu, and Sposi (2018). The outer loop consists of iterating on the labor supply decision and the rate of investment in physical capital. The inner loop consists of iterating on a subset of prices as in Sposi (2012), given the guess for labor supply and investment rates.

First, for the outer loop, guess at the sequence of labor supply and investment rate for every country in every period. Given the labor supply and investment rate, within the inner loop start with an initial guess for the entire sequences of wage vectors and the world interest rate on bonds. Form these two objects, recover all remaining prices and quantities, across countries and throughout time, using optimality conditions and market clearing conditions, excluding the balance of payments condition. Then use departures from the the balance of payments condition to update the wages, and use deviations from intertemporal price relationships to update the world interest rate. Iterate on this until the wages and world interest rate satisfy the balance of payments condition and the intertemporal condition for prices. Then back up to the outer loop and check if the labor supply and investment rate decisions salsify optimality. If not, update the guess at labor supply and investment rate and solve the inner loop again. The details to this procedure follow, making reference to equilibrium conditions in Table C.1.

1. Guess at a sequence of labor supply choices in every country, $\left\{\vec{h}_{t}\right\}_{t=1}^{T}$ with

$$
0<h_{i t} \equiv L_{i t} / N_{i t}<1,
$$


Table C.1: Equilibrium conditions

\begin{tabular}{|c|c|c|}
\hline 1 & $r_{i t} K_{i t}=\alpha \nu_{i t} P_{i t} Y_{i t}$ & $\forall(i, t)$ \\
\hline 2 & $w_{i t} L_{i t}=(1-\alpha) \nu_{i t} P_{i t} Y_{i t}$ & $\forall(i, t)$ \\
\hline 3 & $P_{i t} M_{i t}=\left(1-\nu_{i t}\right) P_{i t} Y_{i t}$ & $\forall(i, t)$ \\
\hline 4 & $P_{i t} Q_{i t}=P_{i t}^{c} C_{i t}+P_{i t}^{x} X_{i t}+P_{i t} M_{i t}$ & $\forall(i, t)$ \\
\hline 5 & $P_{i t} Y_{i t}=\sum_{j=1}^{I} P_{j t} Q_{j t} \pi_{j i t}$ & $\forall(i, t)$ \\
\hline 6 & $P_{i t}=\gamma\left(\sum_{j=1}^{I}\left(\left(A_{j t}\right)^{-\nu_{j t}} u_{j t} d_{i j t}\right)^{-\theta}\right)^{-\frac{1}{\theta}}$ & $\forall(i, t)$ \\
\hline 7 & $P_{i t}^{c}=\frac{P_{i t}}{\chi_{i t}^{c}}$ & $\forall(i, t)$ \\
\hline 8 & $P_{i t}^{x}=\frac{P_{i t}^{i t}}{\chi_{i t}^{x}}$ & $\forall(i, t)$ \\
\hline 9 & $\pi_{i j t}=\frac{\left(\left(A_{j t}\right)^{-\nu_{j t}} u_{j t} d_{i j t}\right)^{-\theta}}{\sum_{\ell=1}^{I}\left(\left(A_{\ell t}\right)^{-\nu_{\ell t}} u_{\ell t} d_{i \ell t}\right)^{-\theta}}$ & $\forall(i, j, t)$ \\
\hline 10 & $\begin{aligned} P_{i t}^{c} C_{i t}+\mathcal{A}_{i t+1} & =\left(r_{i t} K_{i t}-P_{i t}^{x} X_{i t}\right)\left(1-\tau_{i t}^{K}\right)+w_{i t} L_{i t}\left(1-\tau_{i t}^{L}\right) \\
& +\left(1+q_{t}\right) \mathcal{A}_{i t}\left(1-\tau_{i t}^{\mathcal{A}}\right)+T_{i t}\end{aligned}$ & $\forall(i, t)$ \\
\hline 11 & $\mathcal{A}_{i t+1}=\mathcal{A}_{i t}+\mathcal{B}_{i t}$ & $\forall(i, t)$ \\
\hline 12 & $K_{i t+1}=(1-\delta) K_{i t}+\delta_{\sigma}^{1-\lambda}\left(X_{i t}\right)^{\lambda} K_{i t}^{1-\lambda}$ & $\forall(i, t)$ \\
\hline 13 & $\frac{C_{i t+1} / N_{i t+1}}{C_{i t} / N_{i t}}=\beta^{\sigma}\left(\frac{\psi_{i t+1}}{\psi_{i t}}\right)^{\sigma}\left(1-\tau_{i t+1}^{\mathcal{A}}\right)^{\sigma}\left(\frac{1+q_{t+1}}{P_{i t+1}^{c} / P_{i t}^{c}}\right)^{\sigma}$ & $\forall(i, t)$ \\
\hline 14 & $\frac{C_{i t+1} / N_{i t+1}}{C_{i t} / N_{i t}}=\beta^{\sigma}\left(\frac{\psi_{i t+1}}{\psi_{i t}}\right)^{\sigma}\left(\frac{\frac{r_{i t+1}}{P_{i t+1}^{c}}-\left(\frac{P_{i t+1}}{P_{i t+1}^{i}}\right) \Phi_{2}\left(K_{i t+2}, K_{i t+1}\right)}{\left(\frac{P_{i t}^{i}}{P_{i t}^{i}}\right) \Phi_{1}\left(K_{i t+1}, K_{i t}\right)}\right)\left(\frac{1-\tau_{i t+1}^{K}}{1-\tau_{i t}^{K}}\right)^{\sigma}$ & $\forall(i, t)$ \\
\hline 15 & $\frac{L_{i t}}{N_{i t}}=1-\left(\zeta_{i t}\right)^{\phi}\left(1-\tau_{i t}^{L}\right)^{-\phi}\left(\frac{w_{i t}}{P_{c i t}}\right)^{-\phi}\left(\frac{C_{i t}}{N_{c i t}}\right)^{\phi / \sigma}$ & $\forall(i, t)$ \\
\hline 16 & $\mathcal{B}_{i t}=P_{i t} Y_{i t}-P_{i t} Q_{i t}+q_{t} \mathcal{A}_{i t}$ & $\forall(i, t)$ \\
\hline 17 & $T_{i t}=\left(r_{i t} K_{i t}-P_{i t}^{x} X_{i t}\right) \tau_{i t}^{K}+w_{i t} L_{i t} \tau_{i t}^{L}+\left(1+q_{t}\right) \mathcal{A}_{i t} \tau_{i t}^{\mathcal{A}}$ & $\forall(i, t)$ \\
\hline
\end{tabular}

Notes: $u_{j t}=\left(\frac{r_{j t}}{\alpha \nu_{j t}}\right)^{\alpha \nu_{j t}}\left(\frac{w_{j t}}{(1-\alpha) \nu_{j t}}\right)^{(1-\alpha) \nu_{j t}}\left(\frac{P_{j t}}{1-\nu_{j t}}\right)^{1-\nu_{j t}}$ and $\gamma=\Gamma(1+(1-\eta) / \theta)^{1 /(1-\eta)}$, where $\Gamma(\cdot)$ is the Gamma function. $\Phi_{1}\left(K^{\prime}, K\right)$ and $\Phi_{2}\left(K^{\prime}, K\right)$ denote the derivatives of the function $\Phi\left(K^{\prime}, K\right)=\delta^{1-1 / \lambda}\left(\frac{K^{\prime}}{K}-(1-\delta)\right)^{1 / \lambda} K$ w.r.t. the first and second arguments, respectively.

guess a sequence of nominal investment rates, $\left\{\vec{\rho}_{t}\right\}_{t=1}^{T}$ with

$$
0<\rho_{i t} \equiv \frac{P_{i t}^{x} X_{i t}}{r_{i t} K_{i t}+w_{i t} L_{i t}}<1
$$

and guess at a terminal NFA position in each country, $\mathcal{A}_{i T+1}$, with $\sum_{i=1}^{I} \mathcal{A}_{i T+1}=0$. Take these as given for the next sequence of steps.

(a) Guess the entire paths for wages, $\left\{\vec{w}_{t}\right\}_{t=1}^{T}$, across countries, and the world interest rate, $\left\{q_{t}\right\}_{t=2}^{T}$, such that $\sum_{i} \frac{w_{i t} L_{i t}}{1-\alpha}=1$, for all $t$ (world GDP is the numéraire in 
each period.

(b) In period 1 use conditions 1-2 and set $\vec{r}_{1}=\left(\frac{\alpha}{1-\alpha}\right)\left(\frac{\vec{w}_{1} \vec{H}_{1}}{\vec{K}_{1}}\right)$, where the initial stock of capital is predetermined. Compute prices $\vec{P}_{1}, \vec{P}_{1}^{c}, \vec{P}_{1}^{x}$ using conditions $6-8$.

(c) Solve for physical investment, $\vec{X}_{1}$, using the guess for the nominal investment rate together with prices: $\vec{X}_{1}=\frac{\vec{\rho}_{1} \vec{w}_{1} \vec{L}_{1}}{(1-\alpha) \vec{P}_{1}^{x}}$. Given the investment, solve for the next-period capital stock, $\vec{K}_{2}$, using condition 10 . Repeat this set of calculations for period 2 , then for period 3 , and all the way through period $T$ to construct the entire sequence of investment and capital.

(d) Given prices, compute the bilateral trade shares $\left\{\overrightarrow{\vec{\pi}}_{t}\right\}_{t=1}^{T}$ using condition 9 .

(e) This step is slightly more involved. I show how to compute the path for consumption and bond purchases by solving the intertemporal problem of the household. This is done in three parts. First I derive the lifetime budget constraint, second I derive the fraction of lifetime wealth allocated to consumption at each period $t$, and third I recover the sequences for bond purchases and the stock of NFAs.

Deriving the lifetime budget constraint To begin, compute the lifetime budget constraint for the representative household (omitting country subscripts for now). Begin with the period budget constraint from condition 10 and combine it with the NFA accumulation technology in condition 11 and the balanced tax revenue in condition 17 :

$$
\mathcal{A}_{t+1}=r_{t} K_{t}-P_{t}^{x} X_{t}+w_{t} L_{t}-P_{t}^{c} C_{t}+\left(1+q_{t}\right) \mathcal{A}_{t}
$$

Iterate the period budget constraint forward through time and derive a lifetime budget constraint. Given $A_{i 1}>0$, compute the NFA position at time $t=2$ :

$$
\mathcal{A}_{2}=r_{1} K_{1}-P_{1}^{x} X_{1}+w_{1} L_{1}-P_{1}^{c} C_{1}+\left(1+q_{t}\right) \mathcal{A}_{1}
$$

Similarly, compute the NFA position at time $t=3$ :

$$
\begin{aligned}
\mathcal{A}_{3} & =r_{2} K_{2}-P_{2}^{x} X_{2}+w_{2} L_{2}-P_{2}^{c} C_{2}+\left(1+q_{2}\right) \mathcal{A}_{2} \\
\Rightarrow \mathcal{A}_{3} & =r_{2} K_{2}-P_{2}^{x} X_{2}+w_{2} L_{2}+\left(1+q_{2}\right)\left(r_{1} K_{1}-P_{1}^{x} X_{1}+w_{1} L_{1}\right) \\
& -P_{2}^{c} C_{2}-\left(1+q_{2}\right) P_{1}^{c} C_{1}+\left(1+q_{2}\right)\left(1+q_{1}\right) \mathcal{A}_{i 1} .
\end{aligned}
$$


It is useful to define $\left(1+Q_{t}\right)=\prod_{n=1}^{t}\left(1+q_{n}\right)$. By induction, for any time $t$,

$$
\begin{aligned}
\mathcal{A}_{t+1} & =\sum_{n=1}^{t} \frac{\left(1+\mathcal{Q}_{t}\right)\left(r_{n} K_{n}-P_{n}^{x} X_{n}+w_{n} L_{n}\right)}{1+\mathcal{Q}_{n}} \\
& -\sum_{n=1}^{t} \frac{\left(1+\mathcal{Q}_{t}\right) P_{n}^{c} C_{n}}{1+\mathcal{Q}_{n}}+\left(1+\mathcal{Q}_{t}\right) \mathcal{A}_{1} \\
\Rightarrow \mathcal{A}_{t+1} & =\left(1+\mathcal{Q}_{t}\right)\left(\sum_{n=1}^{t} \frac{r_{n} K_{n}-P_{n}^{x} X_{n}+w_{n} L_{n}}{1+\mathcal{Q}_{n}}-\sum_{n=1}^{t} \frac{P_{n}^{c} C_{n}}{1+\mathcal{Q}_{n}}+\mathcal{A}_{1}\right) .
\end{aligned}
$$

Observing the previous expression as of $t=T$ yields the lifetime budget constraint:

$$
\sum_{n=1}^{T} \frac{P_{n}^{c} C_{n}}{1+\mathcal{Q}_{n}}=\underbrace{\sum_{n=1}^{T} \frac{r_{n} K_{n}-P_{n}^{x} X_{n}+w_{n} L_{n}}{1+\mathcal{Q}_{n}}+\mathcal{A}_{1}-\frac{\mathcal{A}_{T+1}}{1+\mathcal{Q}_{T}}}_{\mathcal{W}} .
$$

In the lifetime budget constraint (C.3), $\mathcal{W}$ denotes the net present value of lifetime wealth, taking both the initial and terminal NFA positions as given.

Solving for the path of consumption Next, compute how the net-present value of lifetime wealth is optimally allocated throughout time. For this it is useful to define $\left(1-\mathcal{T}_{t}^{A}\right)=\prod_{n=1}^{t}\left(1-\tau_{n}^{\mathcal{A}}\right)$. The Euler equation for bonds (condition 13) implies the following relationship between any two periods $t$ and $n$ :

$$
\begin{gathered}
C_{n}=\left(\frac{N_{n}}{N_{t}}\right) \beta^{\sigma(n-t)}\left(\frac{\psi_{n}}{\psi_{t}}\right)^{\sigma}\left(\frac{1-\mathcal{T}_{n}^{\mathcal{A}}}{1-\mathcal{T}_{t}^{\mathcal{A}}}\right)^{\sigma}\left(\frac{1+\mathcal{Q}_{n}}{1+\mathcal{Q}_{t}}\right)^{\sigma}\left(\frac{P_{t}^{c}}{P_{n}^{c}}\right)^{\sigma} C_{t} \\
\Rightarrow \frac{P_{n}^{c} C_{n}}{1+\mathcal{Q}_{n}}=\left(\frac{N_{n}}{N_{t}}\right) \beta^{\sigma(n-t)}\left(\frac{\psi_{n}}{\psi_{t}}\right)^{\sigma}\left(\frac{1-\mathcal{T}_{n}^{\mathcal{A}}}{1-\mathcal{T}_{t}^{\mathcal{A}}}\right)^{\sigma}\left(\frac{1+\mathcal{Q}_{n}}{1+\mathcal{Q}_{t}}\right)^{\sigma-1}\left(\frac{P_{t}^{c}}{P_{n}^{c}}\right)^{\sigma-1}\left(\frac{P_{t}^{c} C_{t}}{1+\mathcal{Q}_{t}}\right) .
\end{gathered}
$$

Since equation C.3 implies that $\sum_{n=1}^{T} \frac{P_{i n}^{c} C_{i n}}{1+\mathcal{Q}_{n}}=\mathcal{W}_{i}$, rearrange the previous expression (putting country subscripts back in) to obtain

$$
\frac{P_{i t}^{c} C_{i t}}{1+\mathcal{Q}_{i t}}=\underbrace{\left(\frac{N_{i t} \beta^{\sigma t} \psi_{i t}^{\sigma}\left(1-\mathcal{T}_{i t}^{\mathcal{A}}\right)^{\sigma}\left(1+\mathcal{Q}_{i t}\right)^{\sigma-1}\left(P_{i t}^{c}\right)^{1-\sigma}}{\sum_{n=1}^{T} N_{i n} \beta^{\sigma n} \psi_{i n}^{\sigma}\left(1-\mathcal{T}_{i n}^{\mathcal{A}}\right)^{\sigma}\left(1+\mathcal{Q}_{i n}\right)^{\sigma-1}\left(P_{i n}^{c}\right)^{1-\sigma}}\right)}_{\xi_{i t}} \mathcal{W}_{i} .
$$

That is, in period $t$, country $i$ 's net-present value of consumption spending is a fraction, $\xi_{i t}$, of its lifetime wealth, with $\sum_{t=1}^{T} \xi_{i t}=1$ for all $i$. 
Computing bond purchases and the NFA positions In period 1 take as given consumption spending, investment spending, capital income, labor income, and net income from the initial NFA position; each of which have already been computed in previous steps. Then solve for next period's NFA position, $\overrightarrow{\mathcal{A}_{2}}$, using the period budget constraint in condition 10, then compute net bond purchases $\vec{B}_{2}$ using the period budget constraint in condition 11. Repeat this set of calculations iteratively for periods $2, \ldots, T$.

(f) Given final demand $\left\{\vec{C}_{t}, \vec{X}_{t}\right\}_{t=1}^{T}$ and prices, solve for gross absorption and gross production, $\left\{\vec{Q}_{t}, \vec{Y}_{t}\right\}_{t=1}^{T}$, and intermediate-input demand, $\left\{\vec{M}_{t}\right\}_{t=1}^{T}$ using conditions $3-5$.

(g) Given gross national income, calculate the tax rebates, $\vec{T}_{i t}$, using condition 17.

(h) Update the guesses for wages, the interest rate, and tax rebates.

Balance of payments condition I generalize Alvarez and Lucas (2007) and compute an excess demand equation by imposing that net exports equal the current account less net foreign income from assets.

$$
Z_{i t}^{w}\left(\left\{\vec{w}_{t}, q_{t}\right\}_{t=1}^{T}\right)=\frac{P_{i t} Y_{i t}-P_{i t} Q_{i t}+q_{t} \mathcal{A}_{i t}-\mathcal{B}_{i t}}{w_{i t}} .
$$

Condition 16 requires that $Z_{i t}^{w}\left(\left\{\vec{w}_{t}, q_{t}\right\}_{t=1}^{T}\right)=0$ for all $(i, t)$. If this is different from zero in at some country at some point in time, update the wages:

$$
1+w_{i t}^{n e w}=\Lambda_{i t}^{w}\left(\left\{\vec{w}_{t}, q_{t}\right\}_{t=1}^{T}\right)=\left(1+\kappa \frac{Z_{i t}^{w}\left(\left\{\vec{w}_{t}, q_{t}\right\}_{t=1}^{T}\right)}{L_{i t}}\right) w_{i t}
$$

where $\kappa$ is chosen to be sufficiently small so that $\Lambda^{w}>0$.

Normalizing model units The last part of this step updates the world interest rate. Recall that the numéraire is defined to be world GDP at each point in time: $\sum_{i=1}^{I}\left(r_{i t} K_{i t}+w_{i t} L_{i t}\right)=1$. For an arbitrary sequence of $\left\{q_{t+1}\right\}_{t=1}^{T}$, this condition need not hold. Update the the world interest rate:

$$
q_{t}^{\text {new }}=\Lambda_{i t}^{q}\left(\left\{\vec{w}_{t}, q_{t}\right\}_{t=1}^{T}\right)=\frac{\sum_{i=1}^{I}\left(r_{i t-1} K_{i t-1}+\Lambda_{i t-1}^{w} L_{i t-1}\right)}{\sum_{i=1}^{I}\left(r_{i t} K_{i t}+\Lambda_{i t}^{w} L_{i t}\right)}\left(1+q_{t}\right)-1(t \geq 2)
$$


and $q_{1}^{\text {new }}=q_{1}$. The values for capital stock and the rental rate of capital are computed in step 2, while the values for wages are the updated values $\Lambda^{w}$ above. I set $q_{1}=\frac{1-\beta}{\beta}$ (the interest rate that prevails in a steady state) and chose $A_{i 1}$ so that $q_{1} A_{i 1}$ matches the desired initial NFA position in current prices.

Having updated the wages, the world interest rate, and tax rebates, repeat steps 2a-2g. Iterate through this procedure until the excess demand is sufficiently close to zero. In the computations I find that my preferred convergence metric:

$$
\max _{t=1}^{T}\left\{\max _{i=1}^{I}\left\{\left|Z_{i t}^{w}\left(\left\{\vec{w}_{t}, q_{t}\right\}_{t=1}^{T}\right)\right|\right\}\right\}
$$

converges roughly monotonically towards zero.

2. The last step of the algorithm is to update the labor supply, investment rate, and terminal NFA position. Until now, the optimality condition 15 for the labor supply and condition 14 for the investment in physical capital have not been used. To this end, compute a "residual" from each of these first-order conditions as

$$
\begin{aligned}
Z_{i t}^{h}\left(\left\{\vec{h}_{t}, \vec{\rho}_{t}\right\}_{t=1}^{T}\right) & =\left(1-\frac{L_{i t}}{N_{i t}}\right)-\zeta_{i t}^{\phi}\left(1-\tau_{i t}^{L}\right)^{-\phi}\left(\frac{w_{i t}}{P_{c i t}}\right)^{-\phi}\left(\frac{C_{i t}}{N_{c i t}}\right)^{\frac{\phi}{\sigma}}, \\
Z_{i t}^{\rho}\left(\left\{\vec{h}_{t}, \vec{\rho}_{t}\right\}_{t=1}^{T}\right) & =\beta\left(\frac{\psi_{i t+1}}{\psi_{i t}}\right)\left(1-\tau_{i t+1}^{\mathcal{A}}\right)\left(\frac{\frac{r_{i t+1}}{P_{i t+1}^{c}}-\left(\frac{P_{i t+1}^{x}}{P_{i t+1}^{c}}\right) \Phi_{2}\left(K_{i t+2}, K_{i t+1}\right)}{\left(\frac{P_{i t}^{x}}{P_{i t}^{c}}\right) \Phi_{1}\left(K_{i t+1}, K_{i t}\right)}\right)\left(\frac{1-\tau_{i t+1}^{K}}{1-\tau_{i t}^{K}}\right) \\
& -\left(\frac{C_{i t+1} / N_{i t+1}}{C_{i t} / N_{i t}}\right)^{\frac{1}{\sigma}} .
\end{aligned}
$$

Condition 15 requires that $Z_{i t}^{h}\left(\left\{\vec{h}_{t}, \vec{\rho}_{t}\right\}_{t=1}^{T}\right)=0$ for all $(i, t)$, while condition 14 requires that $Z_{i t}^{\rho}\left(\left\{\vec{h}_{t}, \vec{\rho}_{t}\right\}_{t=1}^{T}\right)=0$. Update the labor supply and investment rate as

$$
\begin{aligned}
& h_{i t}^{\text {new }}=\Lambda_{i t}^{h}\left(\left\{\vec{h}_{t}, \vec{\rho}_{t}\right\}_{t=1}^{T}\right)=\left(1+\kappa Z_{i t}^{h}\left(\left\{\vec{h}_{t}, \vec{\rho}_{t}\right\}_{t=1}^{T}\right)\right) h_{i t}, \\
& \rho_{i t}^{\text {new }}=\Lambda_{i t}^{\rho}\left(\left\{\vec{h}_{t}, \vec{\rho}_{t}\right\}_{t=1}^{T}\right)=\left(1+\kappa Z_{i t}^{\rho}\left(\left\{\vec{h}_{t}, \vec{\rho}_{t}\right\}_{t=1}^{T}\right)\right) \rho_{i t}
\end{aligned}
$$

where $\psi$ is a constant value assigned to ensure that the updated guesses remain positive. Given the updated sequence of labor supply and investment rate, return to step 1 using the updated labor supply and investment rate as the "guess" for the next iteration. Iterate until conditions 14 and 15 hold. 
With $T$ chosen to be sufficiently large, the turnpike theorem implies that the terminal NFA position has minimal bearing on the transition path up to some time $t^{\star}<T$ (see Maliar, Maliar, Taylor, and Tsener, 2015).

\section{Additional figures}

Figure D.1: Working age share

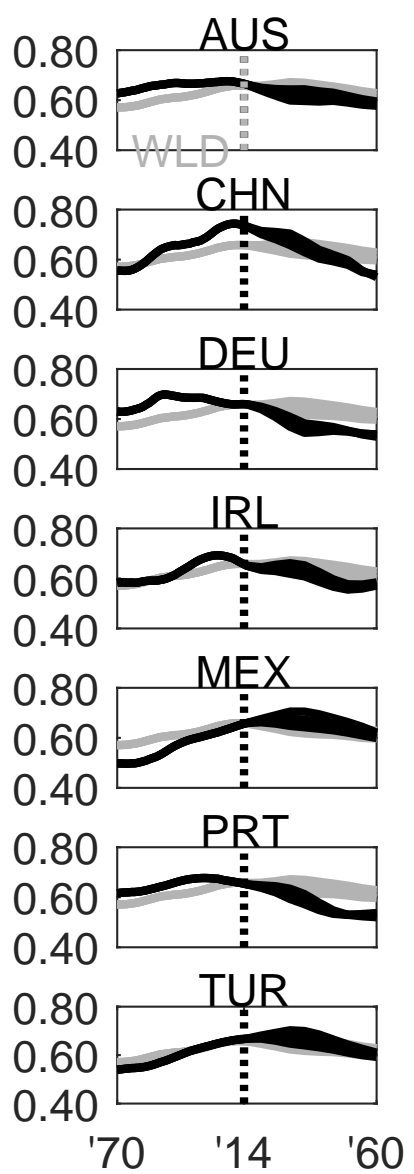

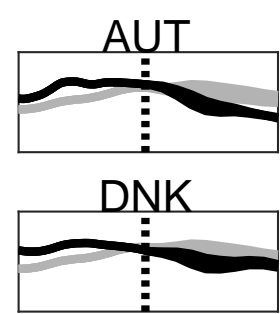

GRC

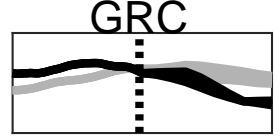

ITA

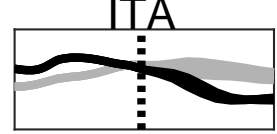

NLD

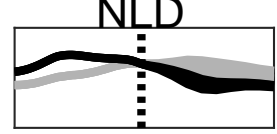

ESP

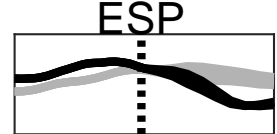

GBR

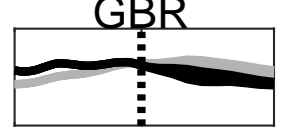

'70 '14 '60

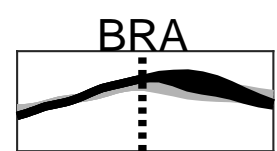

FIN

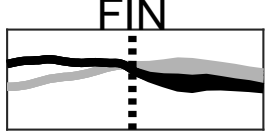

IND

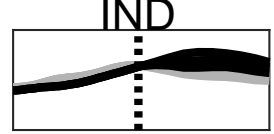

JPN

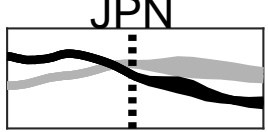

NOR

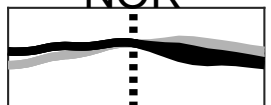

SWE

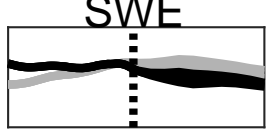

USA

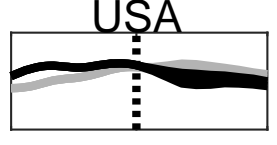

$' 70$
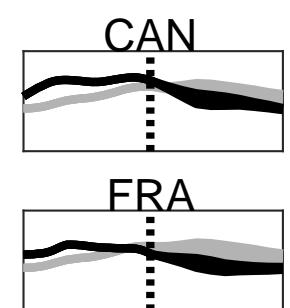

IDN

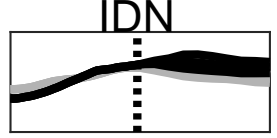

KOR

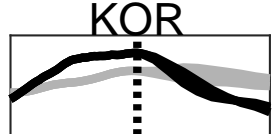

POL

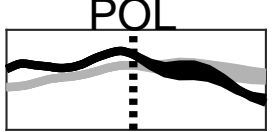

$\mathrm{CHE}$

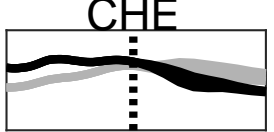

Row

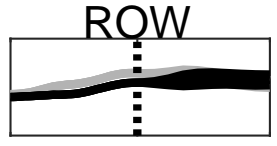

'70 '14 '60

Notes: Black lines - country level. Gray lines - world aggregate. Data from 1970-2014 are observed. Data from 2015-2060 are based on projections: high-variant (upper), medium-variant (middle), and low-variant (lower). High- and low-variants assume plus and minus one-half child per woman, respectively, relative to the medium-variant. 
Figure D.2: Population - indexed to 1 in 2014
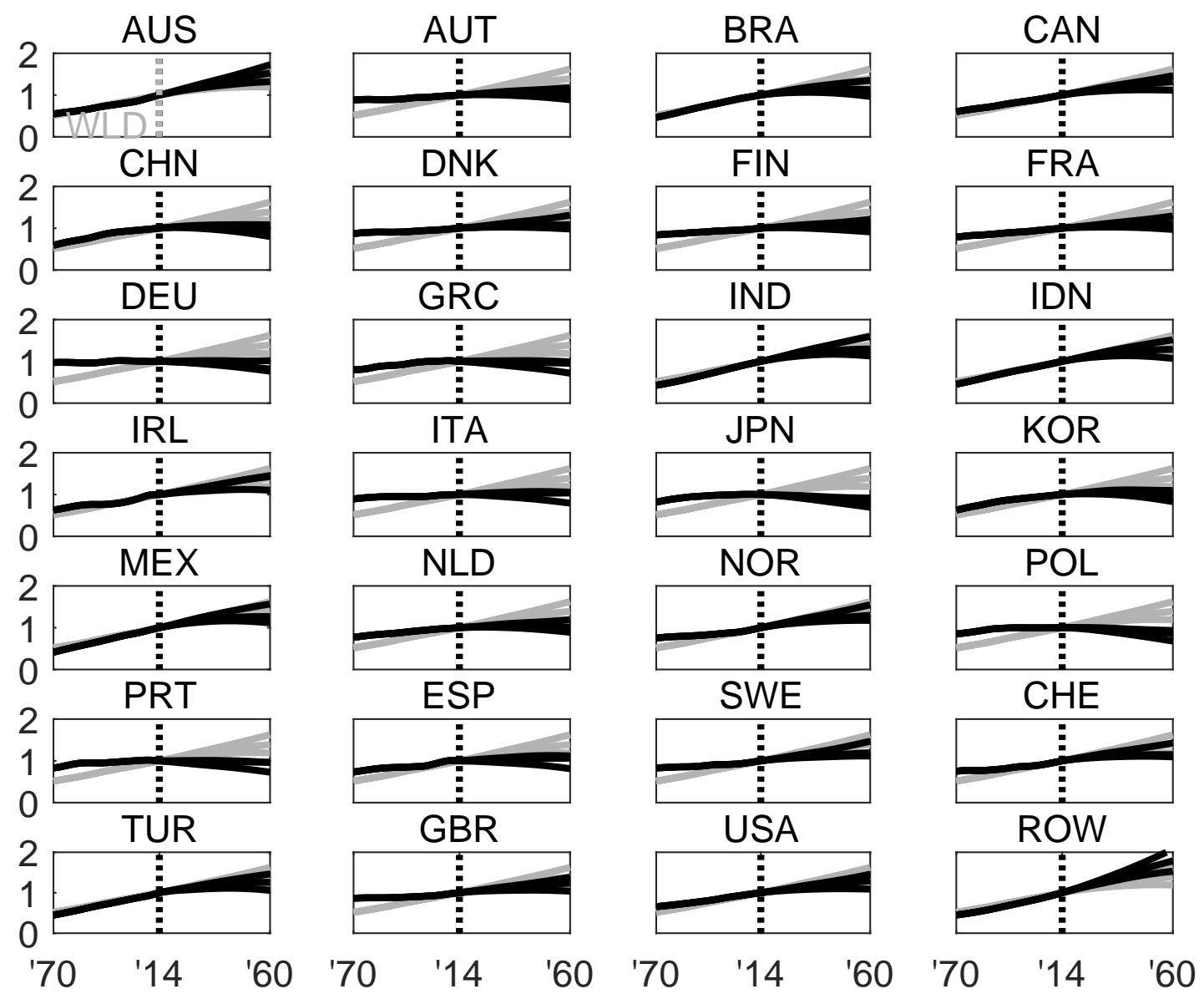

Notes: Black lines - country level. Gray lines - world aggregate. Data from 1970-2014 are observed. Data from 2015-2060 are based on projections: high-variant (upper), medium-variant (middle), and low-variant (lower). High- and low-variants assume plus and minus one-half child per woman, respectively, relative to the medium-variant. 
Figure D.3: Model fit for targeted data: 1970-2014

(a) Log wage

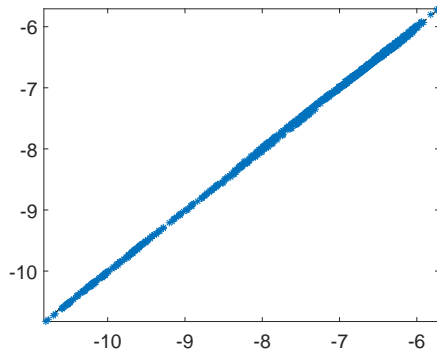

(d) Log employment

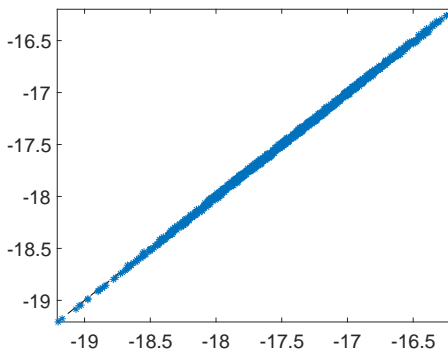

(g) Log price of tradables

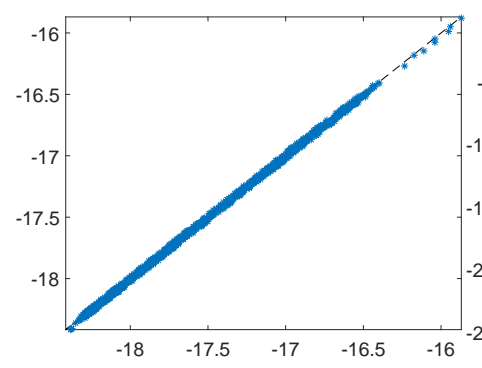

(b) Log price of consumption

(c) Log price of investment
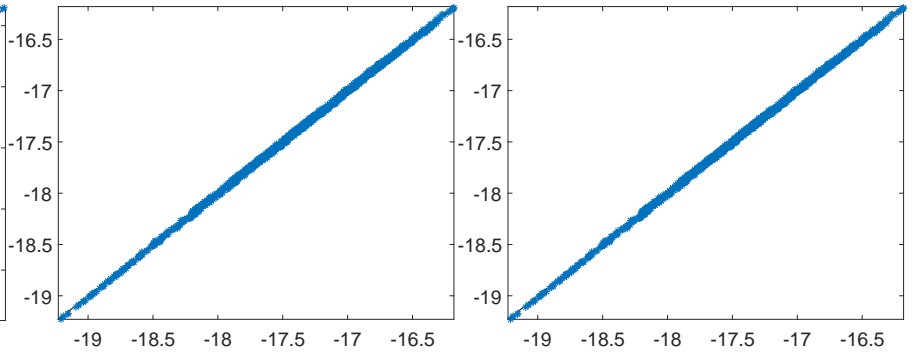

(e) Log consumption

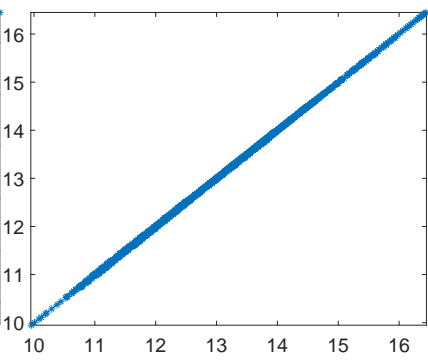

(f) Log investment

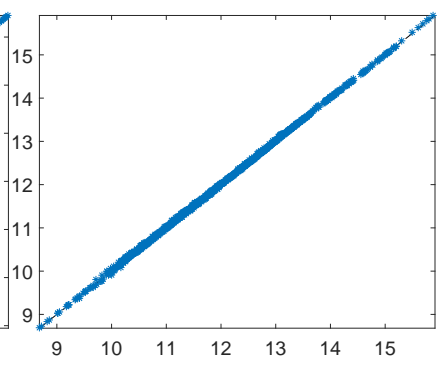

(i) Home trade share

(h) Log bilateral trade flow

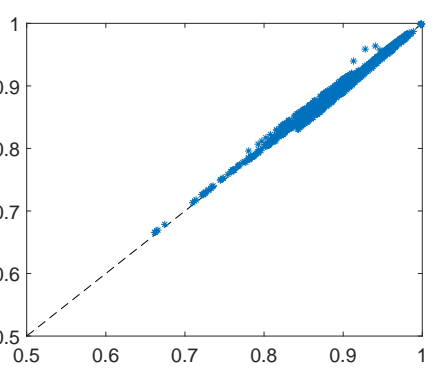

Notes: Horizontal axis - data. Vertical axis - model. Each point corresponds to one country in one year. The dashed line represents the 45-degree line. 
Figure D.4: Ratio of net exports to GDP, baseline and counterfactual

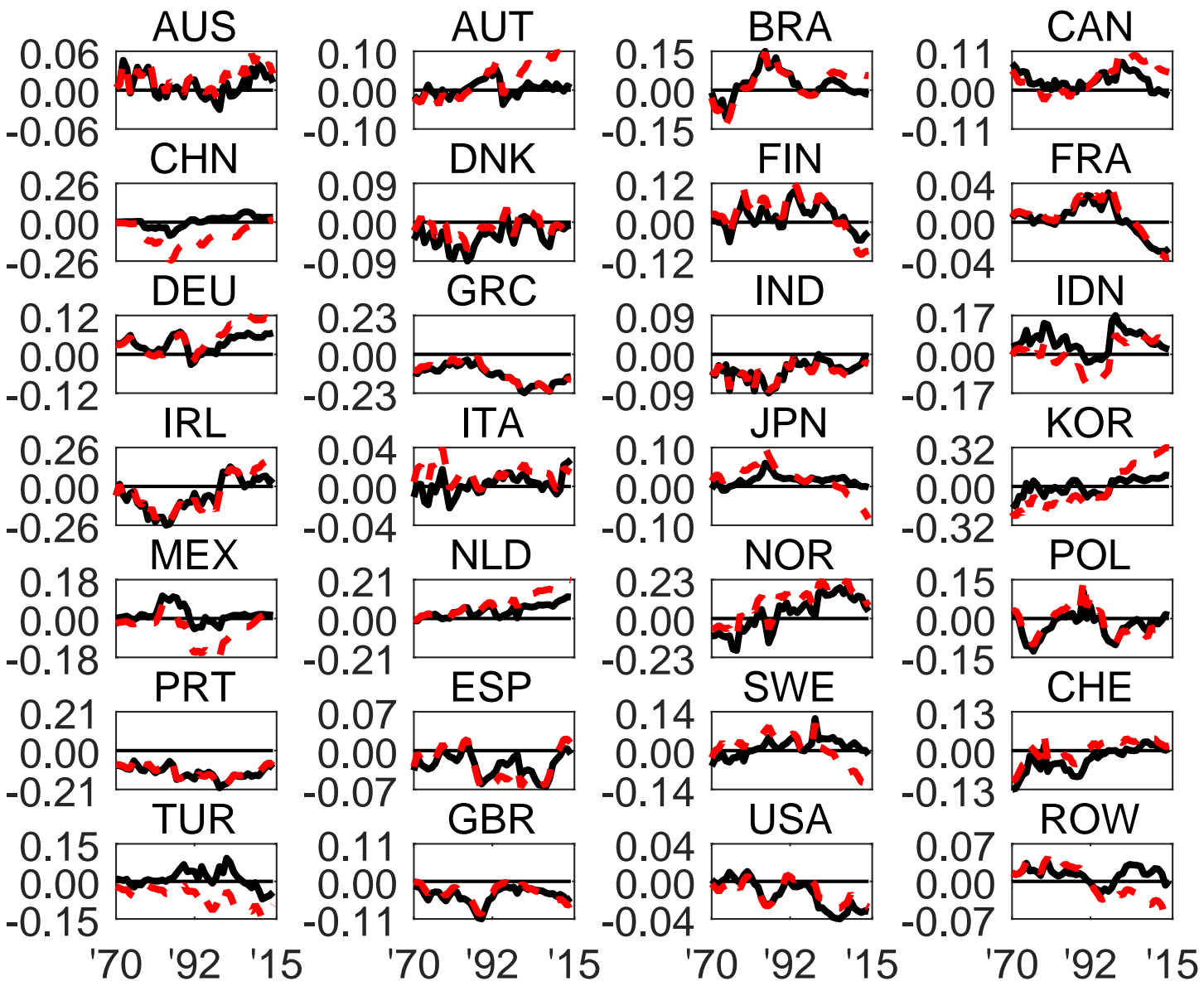

Notes: Solid black lines - baseline (data). Dashed red lines - counterfactual with age distributions simultaneously held constant over time in every country. 